\title{
ALESSANDRA ROGGÉRIO
}

Expressão aumentada dos antígenos de MMP-9, PPAR $\alpha$, Chlamydophila pneumoniae e Mycoplasma pneumoniae em fragmentos ateroscleróticos de aorta com aneurisma

Tese apresentada à Faculdade de Medicina da Universidade de São Paulo para obtenção do título de Doutor em Ciências

Área de Concentração: Cardiologia

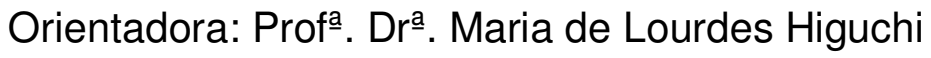

Co-orientadora: Drª . Nádia Vieira Sambiase

São Paulo

2008 


\section{Dados Internacionais de Catalogação na Publicação (CIP)}

Preparada pela Biblioteca da

Faculdade de Medicina da Universidade de São Paulo

Creprodução autorizada pelo autor

\section{Roggério, Alessandra}

Expressão aumentada dos antígenos de MMP-9, PPAR $\alpha$, Chlamydophila pneumoniae e Mycoplasma pneumoniae em fragmentos ateroscleróticos de aorta com aneurisma / Alessandra Roggério. -- São Paulo, 2008.

Tese(doutorado)--Faculdade de Medicina da Universidade de São Paulo.

Departamento de Cardio-Pneumologia.

Área de concentração: Cardiologia.

Orientadora: Maria de Lourdes Higuchi

Co-orientadora: Nádia Vieira Sambiase..

Descritores: 1.Aneurisma aórtico 2.Aterosclerose 3.Metaloproteinase da matriz 4.Receptores ativados por proliferador de peroxissomo 5.Chlamydophila pneumoniae 6.Mycoplasma pneumoniae 7.Imunoistóquímica 
"Para ser grande, sê inteiro, nada teu exagera ou exclui. Sê todo em cada coisa. Põe quanto és no mínimo que fazes. Assim em cada lago a lua toda brilha, porque alta vive."

\section{Fernando Pessoa}


Aos meus pais Marcos e Deoclécia

Pela vida, pelo amor incondicional e apoio em todos os momentos. 
À Profa Dra Maria de Lourdes Higuchi, minha orientadora, pelos anos de aprendizado, pela confiança depositada, pelo incentivo constante, e exemplos profissional e pessoal.

À Dra Nádia Vieira Sambiase, minha co-orientadora, pela amizade, por todos os anos de convivência, por me direcionar nos momentos mais críticos, pela confiança, e experiências profissionais e pessoais compartilhadas.

À Dra Maria Alice Pedreira de Castro, amiga, mãe, conselheira, obrigada por todos estes anos de convivência, paciência e ciência.

Ao querido amigo Gerson Lilá Ramos, obrigada por fazer o dia a dia mais alegre, pela paciência, ombro amigo, auxílio nos momentos mais difíceis, conselhos e pelas ótimas conversas de fim de tarde.

À querida amiga Dra Raquel de Queiroz Fagundes Rodrigues pela amizade, carinho, atenção e cafés... Obrigada por iluminar a todos com o seu sorriso e fazer a vida muito mais interessante.

Á Dra Sueli Blanes Damy, pela amizade, conselhos, discussões científicas, e pela maravilhosa massa.

Aos colegas de pós-graduação, Dra Maria Cristina Abduch pela amizade, pelo carinho, apoio, sugestões e experiências compartilhadas. E ao Dr Luciano Figueiredo Borges, pela amizade e convivência.

Ao Dr Paulo Sampaio Gutierrez, pela correção deste trabalho e valiosas sugestões, não apenas científicas, mas também culturais e gastronômicas. 
Ao Dr Luiz Alberto Benvenuti, pela correção deste trabalho e valiosas sugestões, atenção e confiança.

À Solange Consorte e Adriana Psota pela eficiência e qualidade do seu trabalho, pela amizade, por boas conversas e risadas e pela ajuda em diversos momentos.

Ao Ricardo K. Nakayama, pela amizade incondicional, apoio, presença constante e por todos estes anos de convivência.

Ao Antônio José V. Guedes, pelo carinho, atenção, por sempre ter uma palavra de incentivo e pelas ótimas conversas.

As biologistas Dra Márcia Martins Reis, Suely A. P. Palomino, Renata N. Ikegami, Tatiane Tokunaga e Joyce Tieko Kawakami, pela convivência diária.

Aos médicos do Laboratório de Anatomia Patológica: Dra Lea Maria M. Demarchi, Dra Vera D. Aiello, Dr Mauro Canzian e Dra Jussara B. Castelli.

Aos secretários Francisco Denis Batista e Wagner Bezerra, pela amizade e apoio e incentivo.

Às "meninas" da Comissão de Pós-Graduação Juliana Lattari Sobrinho, Eva Malheiros e Neusa Rodrigues Dini pelas orientações sempre precisas, auxílio, apoio e torcida.

Meu agradecimento especial a todos aqueles que de alguma forma, mesmo que através de apenas um gesto ou uma palavra amiga, me auxiliaram durante esta jornada ao mundo da ciência. 
Lista de Tabelas $\quad$ xi

Lista de Figuras xii

Resumo xiv

Summary $\quad x V$

1. Intodução 1

1.1 Aneurisma 2

1.1.1 Classificação 2

1.1.2 Etiologia e fatores de Risco 3

1.1.3 Características histológicas 4

1.2 Aterosclerose 4

1.3 Aneurisma e o processo aterosclerótico 6

1.4 Aneurisma e metaloproteinases (MMPs)

$\begin{array}{ll}\text { 1.4.1 MMP-9 } & 8\end{array}$

1.5 Receptores ativados por proliferadores de peroxissomos 10

1.6 Presença dos agentes infecciosos na parede vascular 12

$\begin{array}{ll}\text { 2. Objetivos } & 17\end{array}$

3. Material e métodos 19

3.1 Casuística 20

$\begin{array}{ll}3.2 \text { Métodos } & 21\end{array}$

3.2.1 Reação de imuno-histoquímica 22

3.2.1.1 Dupla marcação 23

3.2.2 Análise das reações 25

3.2.3 Análise estatística 26

$\begin{array}{lr}\text { 4. Resultados } & 27\end{array}$

4.1 Análise histológica descritiva das aortas 28

4.1.1 Fragmentos ateroscleróticos sem aneurisma 28

4.1.2 Fragmentos ateroscleróticos com aneurisma 29 
4.2 Análise das medidas de espessuras das camadas da parede vascular

4.3 Análise da quantidade de colágeno na parede vascular

4.4 Análise dos dados semiquantitativos da inflamação na adventícia

4.5 Análise das avaliações quantitativas de antígenos nas diferentes camadas da parede vascular

4.5.1 MMP-9 e TIMP-1

4.5.2 PPARs

4.4.2.1 Dupla marcação para PPARs e macrófagos

4.5.3 Agentes infecciosos: Chlamydophila pneumoniae e Mycoplasma pneumoniae

4.6 Correlações entre colágeno, MMP-9, PPARs e Agentes infecciosos

4.6.1 Correlações significantes no tecido adiposo periadventicial

4.6.2 Correlações significantes na camada adventícia

5. Discussão

5.1 Alterações estruturais da parede vascular

5.2 Metaloproteinase - 9 e Inibidor tecidual da metaloproteinase - 1

5.3 Receptores ativados por proliferadores de peroxissomos

5.4 Agentes infecciosos

5.5 Interações entre colágeno, MMP-9, PPARs e agentes infecciosos

5.6 Adventícia e o desenvolvimento de aneurisma de aorta:

Semelhanças com a placa instável

6. Conclusão

7. Anexos

8. Referências bibliográficas 


\section{LISTA DE TABELAS}

Tabela 1 - Anticorpos e métodos de recuperação utilizados para as reações de imunohistoquímica

Tabela 2 - Média e desvio padrão da espessura em $\mu \mathrm{m}$ da adventícia, média e íntima em G1 e G2

Tabela 3 - Média e desvio padrão da quantidade de colágeno (\% área) na parede vascular em G1 e G2

Tabela 4 - Expressão de MMP-9 na parede vascular e comparação entre G1 e G2

Tabela 5 - Expressão de TIMP-1 na parede vascular e comparação entre G1 e G2

Tabela 6 - Expressão de PPAR a na parede vascular e comparação entre G1 e G2

Tabela 7 - Expressão de PPAR y na parede vascular e comparação entre G1 e G2

Tabela 8 - $\quad$ Media dos valores de \% de área ocupada por Chlamydophila pneumoniae na parede vascular em G1 e G2 e comparação entre os grupos

Tabela 9 - $\quad$ Media dos valores de \% de área ocupada por Mycoplasma pneumoniae na parede vascular em G1 e G2 e comparação entre os grupos

Tabela 10 - Correlações entre MMP-9, TIMP-1, PPAR $\alpha$, PPAR $\mathrm{Y}, \mathrm{CP}$ e MP presentes no tecido adiposo periadventicial

Tabela 11 - Correlações entre colágeno, MMP-9, TIMP-1, PPAR a, PPAR $\gamma$, CP e MP presentes na camada adventícia 


\section{LISTA DE FIGURAS}

Figura 1 - Aspecto histológico do tecido adiposo periadventicial em G1 (1A) e G2 (1B), apresentando intensa inflamação em meio às células adiposas (setas). Coloração de Verhoeff, aumento original 20x.

Figura 2 - Aspecto histológico da adventícia. 2A: G1 exibindo poucas célula inflamatórias, espessamento intimal do vasa vasorum. 2B: G2 exibindo intenso infiltrado inflamatório, principalmente na região do vasa vasorum. Observar espessamento da adventícia de G2 em relação a G1. Coloração de Verhoeff, aumento original $10 x$.

Figura 3 - Visão panorâmica da histologia dos fragmentos de aorta em 3A fragmento aterosclerótico e 3B fragmento aneurismático, com ênfase ao afilamento da média. Coloração de Verhoeff, aumento original $5 x$.

Figura 4 - Aspecto histológico da camada íntima. 4A: G1 exibindo placa com grande núcleo lipídico e capa de fibrose. 4B: G2 com placas sem capa de fibrose trombos na superfície. Coloração de Verhoeff, aumento original de $5 x$ em A e 10 x em $B$.

Figura 5 - Detalhe histológico da camada média em fragmento de G2, enfatizando a neoformação vascular. Aumento original 20x.

Figura 6 - Análise das espessuras, camada adventícia (ADV), camada média (MED) e camada íntima (INT) em G1 e G2.

Figura 7 - Aspecto histológico da camada adventícia. Observar diferença no padrão das fibras de colágeno em $A$ (GI) e em B (GII). Coloração Picrossirius, aumento original 20x.

Figura 8 - Semiquantificação da inflamação na camada adventícia.

Figura 9 - Imuno-histoquímica apresentando células positivas para MMP-9. A tecido adiposo periadventicial de G1; B tecido adiposo periadventicial de G2; C adventícia de G1; D adventícia de G2. Aumento original 40x. 
Figura 10 - Imuno-histoquímica apresentando células positivas para TIMP-1. A tecido adiposo periadventicial de G1; B tecido adiposo periadventicial de G2; C adventícia de G1; D adventícia de G2. Aumento original, 40x.

Figura 11 - Imuno-histoquímica apresentando células positivas para PPAR $\alpha$. A tecido adiposo periadventicial de G1; B tecido adiposo periadventicial de G2; C adventícia de G1; D adventícia de G2. Aumento original, $40 x$.

Figura 12 - Imuno-histoquímica apresentando células positivas para PPAR y. A tecido adiposo periadventicial de G1; B tecido adiposo periadventicial de G2; C adventícia de G1; D adventícia de G2. Aumento original 40x.

Figura 13 - Dupla imunomarcação para CD68 e PPAR $\alpha(A)$ e PPAR $\gamma$ (B). Observar presença de células duplamente marcadas e marcadas individualmente. Aumento original, 40x.

Figura 14 - Imuno-histoquímica apresentando células positivas para Chlamydophila pneumoniae. A tecido adiposo periadventicial de G1; $\mathbf{B}$ tecido adiposo periadventicial de G2; C adventícia de G1; D adventícia de G2. Aumento original, 40x.

Figura 15 - Imuno-histoquímica apresentando células positivas para Mycoplasma pneumoniae. A tecido adiposo periadventicial de G1; $\mathbf{B}$ tecido adiposo periadventicial deG2; C adventícia de G1; D adventícia de G2. Aumento original, 40x. 
Roggério, A. Expressão aumentada de antígenos de MMP-9, PPAR $\alpha$ e Chlamydophila pneumoniae e Mycoplasma pneumoniae em fragmentos ateroscleróticos de aorta com aneurisma [tese]. São Paulo: Faculdade de Medicina, Universidade de São Paulo; 2008. 107p.

Introdução: Aneurisma de aorta é considerado uma doença inflamatória crônica, mas ainda é controverso se está relacionado a aterosclerose aos agentes infecciosos. Antígenos de Chlamydophila pneumoniae (CP) e Mycoplasma pneumoniae (MP) foram encontrados em grande quantidade nas placas instáveis que usualmente estão associadas a remodelamento positivo e inflamação do vaso. Metaloproteinase da matriz 9 (MMP-9) está implicada na fragilidade da parede vascular e na formação dos aneurismas. Os efeitos imunomodulatórios dos receptores ativados por proliferador de peroxissomo (PPARs) têm sido relacionados à aterosclerose. Objetivos: Comparar lesões ateroscleróticas graves com e sem aneurisma do ponto de vista inflamatório e infeccioso, analisando antígenos de MP e CP e expressão de MMP-9, TIMP-1 e PPARs. Métodos: No presente estudo quantificamos, através da técnica de imunoistoquímica, antígenos de MMP9, TIMP-1, PPARs $\alpha$ e $y$, e dos agentes infecciosos CP e MP em fragmentos de aorta ateroscleróticos com aneurisma $(n=14)$ e sem aneurisma $(n=14)$. Resultados: A adventícia e o tecido adiposo periadventicial (TAP) dos aneurismas apresentaram intensa inflamação. Expressão de MMP-9 esteve aumentada no TAP e agentes infecciosos, TIMP-1 e PPAR $\alpha$ estiveram aumentados na adventícia e no TAP, sem diferença em relação a expressão de PPAR y. Colágeno, TIMP-1 e PPARs estiveram positivamente correlacionados no grupo com aterosclerose, mas não no grupo com aneurisma. Conclusão: Nossos achados sugerem que aneurisma de aorta é uma complicação das lesões ateroscleróticas. Quantidade aumentada de Chlamydophila pneumoniae e Mycoplasma pneumoniae na adventícia e PAT sem correlação da resposta de TIMP-1 e PPARs são achados que estão associados com a presença de aneurisma nos segmentos de aorta ateroscleróticos.

Descritores: Aneurisma aórtico, Aterosclerose, Metaloproteinase da matriz9, Receptores ativados por proliferadores de peroxissomo, Chlamydophila pneumoniae, Mycoplasma pneumoniae, Imunoistoquímica 
Roggério, A. Increased expression of MMP-9, PPAR $\alpha$ and Chlamydophila pneumoniae e Mycoplasma pneumoniae antigens in atherosclerostic aortic fragments with aneurysms [thesis]. São Paulo: "Faculdade de Medicina, Universidade de São Paulo", 2008. 107p.

Introduction: Aortic aneurysm is considered a chronic inflammatory disease, but remains a controversial matter if it is related to atherosclerosis and infectious agents. Chlamydophila pneumoniae (CP) and Mycoplasma pneumoniae (MP) antigens were found in higher amount in unstable plaques that are usually associated to positive remodeling and vessel inflammation. Matrix metalloproteinase 9 (MMP-9) has been implicated in vascular wall fragility and aneurysm development. The immunemodulator effects of peroxisome proliferators - activated receptor (PPARs) have been related to atherosclerosis. Objectives: To compare severe atherosclerotic lesions with and without aneurysms by inflammatory and infectious point of view, analyzing MP and CP, MMP-9, TIMP-1 and PPARs antigens. Methods: In the present study we quantified, using immunohistochemistry technique, MMP-9, TIMP-1, PPAR $\alpha$ and $y$ and infectious agents CP and MP antigens in aortic atherosclerotic fragments with aneurysms. $(n=14)$ and without aneurysms $(n=14)$. Results: Adventitia and periadventitial adipose tissue (PAT) from aneurysms showed intense inflammation. MMP-9 expression has increased in PAT and the infectious agents, TIMP-1 and PPAR $\alpha$ were increased in adventitia and PAT in aneurysmatic group, without difference related to PPAR y expression. Collagen, TIMP-1 and PPARs were positively correlated in atherosclerotic group, but it was not observed in aneurysmatic group. Conclusion: Our data have suggested that aortic aneurysm is a complication of aortic atherosclerotic lesions. Increased amount of Chlamydophila pneumoniae and Mycoplasma pneumoniae in the adventitia and PAT without a correlated TIMP-1 and PPARs response are findings that were associated with the presence of aneurysm in atherosclerotic aortic segments.

Descriptors: Aortic aneurysm, Atherosclerosis, Matrix metalloproteinase-9, Peroxisome proliferators - activated receptors, Chlamydophila pneumoniae, Mycoplasma pnemoniae, Imunohistochemistry 


\section{Introdução}




\subsection{ANEURISMA}

Aneurisma por definição é uma dilatação anormal de um segmento vascular ou da parede do coração. Primeiramente descrito por Galeno (131200 d.C.), o aneurisma é reconhecido como uma lesão local, permanente, irreversível, caracterizada como uma dilatação que excede uma vez e meia o diâmetro normal do vaso. Qualquer tipo de vaso ou porção dele pode ser acometido, mas preferencialmente, são comprometidas as artérias cerebrais, e a aorta (Sakalihasan, 2005). Essa lesão desenvolve-se lentamente, com dilatação progressiva, aumentando seu volume, podendo causar rompimento da parede vascular e provocar intensa hemorragia. Além disso, pode comprimir, deslocar e destruir estruturas vizinhas (Filho, 2000).

Aneurismas da aorta são os mais comuns, sendo encontrados em toda a sua extensão. São mais freqüentes na aorta abdominal, abaixo das artérias renais e acima da bifurcação das artérias ilíacas, quando comparados à porção torácica (Bettmann, 2004). Aneurismas com diâmetro superior a $6,0 \mathrm{~cm}$ apresentam um risco de ruptura de $17 \%$ ao ano, sendo responsáveis por 15.000 mortes ao ano nos Estados Unidos (Sakalihasan, 2005).

\subsubsection{Classificação}

São classificados de acordo com sua morfologia, localização e etiologia. Aneurisma verdadeiro é aquele que compromete toda a espessura da parede vascular, causando alterações em seus componentes. Dilatação 
vascular por delaminação das camadas da parede vascular por infiltração sanguínea não é um verdadeiro aneurisma, mas sim dissecção (Schoen, 2005). Do ponto de vista morfológico, os aneurismas podem se apresentar como dilatações saculiformes de uma porção da parede, ou fusiformes com um comprometimento de todo o diâmetro vascular (Nobre, 2005). Quanto à localização anatômica, os aneurismas de aorta ascendente, arco e descendente torácica são denominados aneurismas de aorta torácica e os que acometem a porção da aorta logo abaixo do diafragma são denominados aneurismas de aorta abdominal (Guo, 2006).

\subsubsection{Etiologia e fatores de risco}

Diversos fatores etiológicos podem estar ligados ao desenvolvimento, expansão e ruptura dos aneurismas. Com freqüência bem menor os aneurismas podem ser conseqüências diretas de causas específicas como trauma, infecção aguda, doenças inflamatórias (arterite de Takayasu e Behçet) e desordens do tecido conectivo (Síndrome de Marfan e EhlersDanlos tipo IV) (Shimizu, 2006).

A aterosclerose é o principal fator associado aos aneurismas inespecíficos. A injúria aterosclerótica quase sempre presente nos aneurismas tem levado à postulação de os aneurismas serem na realidade um processo de agravamento da aterosclerose. No entanto, muitos pacientes que possuem doença aterosclerótica oclusiva da aorta não

desenvolvem aneurismas. Assim, acredita-se que outros fatores podem 
estar associados ou influenciando como sexo, idade, hipertensão, predisposição genética e infecções (Libby, 2001).

Com relação ao aneurisma de aorta abdominal, os fatores de risco mais freqüentes são os mesmos relacionados ao desenvolvimento da aterosclerose. O tabagismo é considerado o fator de risco ambiental isolado de maior importância. Dados clínicos mostram aumento da prevalência de aneurisma de até quatro vezes em indivíduos fumantes (Choke, 2005).

\subsubsection{Características histológicas}

Histologicamente, os aneurismas apresentam perda da estrutura normal da parede vascular, acometendo as túnicas íntimas, média e adventícia, com fragmentação das lâminas elásticas da média, perda de células musculares lisas, em associação com presença de lesões ateroscleróticas e remodelamento da matriz extracelular (Chan, 2005; Alexander, 2004; Freestone, 1997; Bernucci, 1992). Além disso, geralmente é observado aumento do número de vasos do vasa vasorum, e inflamação crônica na camada adventícia constituída principalmente por linfócitos ( $\mathrm{T}$ e B), macrófagos e células dendríticas (Shimizu; 2005 e 2006; Thompson, 1996).

\subsection{ATEROSCLEROSE}

A aterosclerose é uma doença secundária à disfunção endotelial seguida por acúmulo de lípides no interior da camada íntima. A disfunção 
endotelial pode estar associada a inúmeras causas como, por exemplo, distúrbios hemodinâmicos, hipertensão arterial, shear stress, diabetes mellitus, tabagismo, hipóxia, agentes infecciosos e homocisteinemia (Filho, 2006). Em conseqüência da disfunção há um aumento na permeabilidade do endotélio, favorecendo a passagem de lipoproteínas de baixa densidade (LDL) para a íntima. A presença das lipoproteínas oxidadas no espaço subendotelial sinaliza a expressão das moléculas de adesão na superfície das células endoteliais, sendo as principais: molécula de adesão celular vascular-1 (VCAM-1), molécula de adesão intercelular-1 (ICAM-1), Eselectina, P-selectina e L-selectina (Libby, 2001). A presença destas moléculas aumenta o recrutamento das células inflamatórias, principalmente de monócitos e linfócitos para o local da lesão.

No espaço intimal, os monócitos, sob influência do fator estimulante de colônia de macrófagos (CSF-M), transformam-se em macrófagos e passam a expressar scavenger receptors englobando e modificando a LDL oxidada, e assim transformando-se em células espumosas. (Luster, 1998; Libby, 2004). A formação e a replicação das células espumosas na íntima caracterizam a aterosclerose insipiente, reconhecidas à macroscopia por "estrias gordurosas".

As células espumosas secretam diversos mediadores inflamatórios que amplificam a inflamação vascular e contribuem para um acúmulo adicional de leucócitos, proliferação de células musculares lisas, e remodelamento da matriz extracelular levando à progressão da lesão (Libby, 2004). Entretanto, essas lesões podem evoluir para uma extensa 
degradação das lâminas elásticas da camada média, acompanhada de intenso infiltrado inflamatório constituído predominantemente por macrófagos, linfócitos e células dendríticas, localizado principalmente na camada adventícia. Esta inflamação está associada a apoptose de células musculares lisas, elevada atividade de citocinas, integrinas e quimiocinas, como PGE-2, fator de necrose tumoral $\alpha$ (TNF $\alpha$ ), interleucina - 6 (IL-6) e IL$1 \beta$ e também tem sido observada nos aneurismas (Alexander, 2005; Shimizu, 2005).

\subsection{ANEURISMA E O PROCESSO ATEROSCLERÓTICO}

Estudo em fragmentos de aorta abdominal realizado por Zarins et al (2001) mostrou uma forte associação entre a aterosclerose, tamanho da aorta e degeneração da camada média. Os autores demonstraram que no local da lesão há danos da microarquitetura normal da média, erosão e enfraquecimento da parede vascular, predispondo à formação de aneurismas.

Os aneurismas considerados inespecíficos comumente se desenvolvem na aorta abdominal em locais com aterosclerose intensa, apresentando placas de grande centro necrótico com freqüente ruptura ou ulceração (Filho, 2000). A camada média apresenta marcado afilamento ou interrupções, com inflamação crônica da camada adventícia (Freestone, 1997) 
Alguns autores têm descrito aneurismas inflamatórios aonde a resposta inflamatória é mais exacerbada (Hayashi, 2006; Hellmann, 2007). Inicialmente considerados uma variante dos aneurismas ateroscleróticos, até o presente momento ainda não está claro se aneurismas inflamatórios podem representar um processo inflamatório periaórtico independente da aterosclerose, caracterizado por fibrose e inflamação da adventícia (Koch, 1990).

Análises das áreas linfóides na camada adventícia indicam presença de linfócitos T, macrófagos, células B e dendríticas. Estas áreas funcionam como locais de resposta imune celular e humoral (Forester, 2005). A presença destas células na parede vascular leva à indução de citocinas inflamatórias (IL-1 $\beta$, IL-6, IL-8, TNF $\alpha$, RANTES e MCP-1), expressão de moléculas de adesão, liberação de espécies reativas de oxigênio e expressão aumentada de proteases (Lindholt, 2006). Ativadores de plasminogênio, serina-elastases e metaloproteinases parecem desempenhar um papel fundamental na gênese dos aneurismas (Eagleton, 2006).

\subsection{ANEURISMAS E METALOPROTEINASES (MMPs)}

As MMPs são endopeptidases zinco-dependentes que degradam componentes da matriz extracelular. A maioria das MMPs é sintetizada e secretada como pró-enzimas inativas e que são ativadas no espaço extracelular por proteinases e outras MMPs (Lijnen, 2004). Estão envolvidas em uma variedade de processos fisiológicos, incluindo inflamação e 
remodelamento de proteínas estruturais. São produzidas por células inflamatórias como neutrófilos e macrófagos, além de células mais indiferenciadas como células neoplásicas e fibroblastos transformados (Keeling, 2005).

Inicialmente proposto por Sênior et al (1991), as MMPs têm sido relacionadas à degeneração da parede arterial, e diretamente implicadas na formação e expansão dos aneurismas. A presença de várias MMPs tais como MMP-2, -3, -8, -9, -12 e -13 (Choke, 2005) já foram descrita nos aneurismas, sendo a MMP-9 a mais estudada.

\subsubsection{MMP-9}

Também conhecida como gelatinase B, a MMP-9 apresenta como substratos principais os colágenos tipos: I, IV, V, VII e X, fibrinogênio e elastina (Keeling, 2005). Produzida por neutrófilos, macrófagos, e outras células inflamatórias, quando estimuladas por IL-1ß, IL-6 e TNFa (Shah, 1997) é encontrada em pequenas quantidades no tecido aórtico normal, estando associada à inflamação crônica e grande quantidade de macrófagos (Thompson, 1995).

Estudos recentes demonstraram associação da MMP-9 ao remodelamento cardíaco (Yan, 2006), instabilidade (Sluijter, 2006), e ruptura da placa aterosclerótica (Leclercq, 2007). Também tem sido encontrada em diferentes estágios de desenvolvimento dos aneurismas (McMillan, 1997; Wilson, 2006). 
Níveis plasmáticos de MMP-9 encontram-se aumentados em indivíduos portadores de aneurisma de aorta abdominal quando comparados com indivíduos normais (Hovsepian, 2000). Além disso, há uma forte correlação entre MMP-9 e aneurismas tanto em tecidos humanos como em modelos animais (Yamashita, 2001). Camundongos knock out para MMP-9 mostram resistência à formação de aneurismas, resistência esta que é perdida ao receberem transplante de medula óssea, tornando-se susceptíveis à formação dos mesmos. Estes resultados suportam a hipótese de que a presença de MMP-9 inflamatória é importante na formação de aneurismas de aorta abdominal (Pyo, 2000).

A atividade das metaloproteinases no ambiente extracelular é regulada em diversos níveis, incluindo alteração na expressão gênica, impedimento da conversão da pró-enzima para a forma ativa e formação de complexos com inibidores específicos como os TIMPs. (Andrian, 2007) Os TIMPs ("tissue inhibitors of matrix metalloproteinases" - inibidores teciduais das metaloproteinases da matriz) são inibidores naturais das metaloproteinases e geralmente são secretados em conjunto (Keeling, 2005). Até a presente data, foram identificados quatro membros desta família de inibidores (TIMP-1, -2, -3 e -4), sendo o TIMP-1 responsável pela inibição da MMP-9 (Orbe, 2003).

A associação do TIMP-1 com as metaloproteinases é rápida, formando complexos reversíveis (1:1), enquanto que a dissociação é lenta, levando assim há uma inibição efetiva da sua atividade (Hornebeck, 2005). O TIMP-1 é expresso no tecido arterial (Meng, 2006) e sob condições 
normais há um delicado balanço entre as duas proteínas, permitindo assim, a homeostase normal da matriz extracelular (Tan, 2007). Por este motivo, alterações nos níveis dos TIMPs são importantes nas condições patológicas associadas a alterações na atividade das metaloproteinases (Visse, 2003).

O conceito atual de que a formação de aneurismas é resultado de um processo inflamatório crônico, com degradação e transformação da parede vascular tem atraído a atenção para o TIMP-1, propondo-se a ocorrência de um desequilíbrio entre MMP-9 e TIMP-1 nessa alteração vascular (Hobeika, 2007). Reforçando o esse conceito, Allaire et al (1998), utilizando um modelo experimental de ratos, demonstrou que o TIPM-1 previne a degradação da elastina, formação de aneurisma e sua ruptura, sugerindo um possível efeito protetor.

Além dos TIMPs, substâncias como TGF- $\beta$, heparina e corticosteróides podem ter ação inibitória sobre as MMPs (Dollery, 1995). Zhang et al (2007) demonstraram ação inibitória de PPARs $\alpha$ e $\gamma$ na síntese de MMP-9 durante a diferenciação de monócitos para formação das células espumosas (foam cells). Esta função pode contribuir para a estabilização da placa instável (Soumian, 2005).

\subsection{RECEPTORES ATIVADOS POR PROLIFERADORES DE PEROXISSOMOS (PPARS)}

PPARs são fatores de transcrição pertencentes à superfamília de receptores nucleares relacionados aos receptores de hormônio retinóides, 
esteróides e tireoidianos (Kota, 2005; Marxs, 2004). São ativados em resposta a ácidos graxos, ácido araquidônico e seus metabólitos eicosanóides, como as prostaglandinas, tromboxinas e leucotrienos e fibratos (Berger, 2002).

Até o presente momento, três isoformas foram identificadas: PPAR $\alpha$, PPAR $\beta / \delta$ e PPAR $\gamma$, que são codificados por diferentes genes e distribuídos em diversos tecidos de acordo com seus subtipos. PPAR $\alpha$ é encontrado principalmente no fígado, rins e músculos esquelético e cardíaco. PPAR $\gamma$ é encontrado predominantemente em adipócitos e células do sistema imune, tais como monócitos/macrófagos, linfócitos B e T e células dendríticas. PPAR $\beta / \delta$ estão distribuídos de forma ampla (Kiec-Wilk, 2005).

Estudos recentes mostram participação do PPAR $\alpha$ e PPAR $\gamma$ na inflamação e aterogênese, estando presentes em células da parede arterial e também em macrófagos (células espumosas) no interior da lesão (Marx, 1998).

O papel biológico destes receptores é ainda muito discutido. De acordo com Moore e colaboradores (2001), no processo de aterosclerose os PPARs são capazes de influenciar vários tipos celulares, como as células endoteliais, macrófagos, células musculares lisas e a resposta vascular a vários fatores. Assim, os PPARs mostram-se intimamente relacionados à formação de células espumosas e à estabilidade da placa (Wakino, 2001). Enquanto o PPAR $\alpha$ diminui os níveis de proteínas pró-ateroscleróticas como fibrinogênio e proteína $C$ reativa, o PPAR $\gamma$ reduz a expressão de metaloproteinases, induzindo a estabilização da placa. Por outro lado, PPAR 
$\gamma$ pode desempenhar um papel pró-aterogênico pela estimulação da LDL oxidada (LDL-ox) captada pelos macrófagos (Kersten, 2000).

As LDL-ox contêm altas concentrações de derivados lipídicos oxidados que são indutores da expressão e ativadores diretos do PPAR $\gamma$. A ativação do fator de transcrição nuclear do PPAR $\gamma$ induz um ciclo que perpetua a lesão aterosclerótica, por desencadear a expressão de receptores CD36, com crescente internalização de moléculas LDL-ox contendo ativadores do PPAR $\gamma$ adicionais (Tontonoz, 1998). Diferentemente, estudos realizados por Chinetti e colaboradores (2001) demonstraram que PPAR $\gamma$ e PPAR $\alpha$ não induzem a formação de células espumosas, apesar dos seus efeitos sobre a expressão de CD36.

Recentemente Huang et al (2005) demonstraram expressão aumentada de PPAR $\gamma$ em células endoteliais da aorta de camundongos C57bL/6J infectados com Chlamydophila pneumoniae e/ou submetidos à dieta aterogênica. Esses dados sugerem uma associação entre a expressão de PPAR $\gamma$ e a infecção por Chlamydophila pneumoniae na patogenia desse modelo de aterosclerose experimental.

\subsection{PRESENÇA DE AGENTES INFECCIOSOS NA PAREDE VASCULAR}

A participação da inflamação na patogenia da aterosclerose e na evolução para instabilidade da placa é hoje um conceito indiscutível (Achneck, 2005). Por outro lado, a causa desta inflamação ainda é 
desconhecida (Espinola-Klein, 2002). Agentes infecciosos ou seus produtos têm sido considerados iniciadores dessa inflamação na parede vascular, onde citomegalovirus, Helicobacter pylori, e Chlamydophila pneumoniae já foram observados (Fong, 2000; Mazur, 2004; Pupka, 2004).

Chlamydophila pneumoniae é uma causa comum de infecções do trato respiratório. Inicialmente proposto por Saikku et al (1988), e depois confirmado por vários autores, observou-se uma íntima associação entre a Chlamydophila pneumoniae e o surgimento / agravamento das lesões ateroscleróticas (Higuchi, 2000; Shi, 2002, Choi, 2002; Gois, 2006). Diversos estudos soroepidemiológicos mostraram níveis elevados de anticorpos anti Chlamydophila pneumoniae em indivíduos com doença arterial coronariana (Kol, 1998; Lindholt, 2001). Embora os eventos moleculares e celulares envolvidos na interação da Chlamydophila pneumoniae e aterogênese sejam ainda pouco conhecidos, acredita-se que este patógeno contribui para o processo da doença atuando como um agente iniciador (Halme, 1999). Este agente foi demonstrado em lesões ateroscleróticas de carótidas e aneurismas de aorta utilizando-se os métodos de imunohistoquímica, hibridização in situ, microscopia eletrônico e PCR (Juvonen, 1997; Higuchi 2000; Higuchi 2002; Higuchi 2003; Espinola-Klein, 2002; Takemoto, 2005). Também se observou que heat shock protein (HSP) de Chlamydophila pneumoniae é capaz de estimular a secreção de citocinas e MMPs pelos macrófagos e aumentar as funções pró-coagulantes do endotélio e de células musculares lisas (Tambiah, 2002). A hiper expressão de MMP-9 foi observada em placas ateroscleróticas instáveis em associação com 
Chlamydophila pneumoniae, inflamação e apoptose (Stintzing, 2005). Estudos in vitro demonstraram que Chlamydophila pneumoniae aumenta a produção de MMPs por estímulos das citocinas IL-6 e IL-1 (Kim, 2005; Schmidt, 2006).

Estudos através da microscopia eletrônica detectaram que Chlamydophila pneumoniae geralmente está associada a micoplasmas, principalmente na adventícia dos vasos, na superfície endotelial do vasa vasorum e no núcleo lipídico das placas vulneráveis, em correlação com remodelamento positivo e inflamação. (Higuchi, 2000 e 2003).

Essa associação entre Chlamydophila pneumoniae e Mycoplasma pneumoniae também foi encontrada em lesões ateroscleróticas iniciais da aorta ascendente, sugerindo participação destes agentes não só no desenvolvimento de complicações da placa, mas também na aterogênese (Góis, 2006). Nesse trabalho, correlação positiva entre número de células infectadas pela Chlamydophila pneumoniae com números de linfócitos T (CD4 e CD8) e B (CD20) e macrófagos (CD68) sugere que a associação entre Chlamydophila pneumoniae e Mycoplasma pneumoniae pode estar relacionada ao desenvolvimento da aterosclerose e inflamação.

Micoplasmas são os menores microrganismos auto-replicantes conhecidos, com o menor genoma entre os procariontes (menos de $600 \mathrm{~kb}$ ), como conseqüência muitas substâncias necessárias para sua sobrevivência não são produzidas. Assim sendo, todas as espécies são parasitas, com patogenicidade variável a cada espécie (Razin; 1994). 
Em humanos, micoplasmas estão associados a pneumonias comunidade-adquirida (Hardegger; 2000), porém têm sido relacionados a outras doenças como febre pós-aborto, doença inflamatória pélvica, pielonefrite, uretrite, mortalidade perinatal, infertilidade, artrite, co-fator do vírus HIV, câncer (Chan, 1996) e aterosclerose (Higuchi; 2000 e 2002; Mahara, 2000).

Micoplasmas são capazes de modular o sistema imune do hospedeiro podendo atuar tanto na supressão deste através da depleção de arginina, citotoxicidade contra células linfóides e diminuição na regulação das citocinas (down-regulation), quanto na ativação do sistema imune através de células natural killers, monócitos/macrófagos e estimulação de citocinas próinflamatórias. Esta habilidade de imunomodulação contribui para suas propriedades patogenéticas, conseguindo driblar os mecanismos de defesa e estabelecer uma infecção crônica persistente (Razin, 1998).

Estudos realizados sobre a ativação de macrófagos/monócitos por micoplasmas mostraram que as lipoproteínas presentes na membrana celular são os seus principais ativadores (Rottem, 2003). Sua membrana celular é rica em lipoproteínas, sendo consideradas altamente antigênicas. Para síntese destas lipoproteínas de membrana há necessidade de grandes quantidades de ácidos graxos e colesterol (Razin, 1998). Desta forma, a necessidade de colesterol para sobrevivência dos micoplasmas pode explicar a presença de grande quantidade destes microorganismos no interstício da parede vascular e no interior do núcleo lipídico da lesão aterosclerótica grave (Higuchi, 2000 e 2003). Estas lipoproteínas induzem a 
liberação de citocinas inflamatórias tais como IL-1 $1 \beta$, IL-6, TNF $\beta$, IL-8, proteína quimiotáxica monocitária (MCP-1), proteína 1 inflamatória de macrófagos (MIP-1 $\alpha$ ), fatores estimulantes de colônia (GM-CSF), prostaglandinas e óxido nítrico (Broaders, 2006, Razin, 1998).

O parasitismo dos micoplasmas na célula hospedeira pode causar diversos danos à célula infectada cujos mecanismos se assemelham aos presentes no desenvolvimento das lesões ateroscleróticas tais como:

a. alterações no citoesqueleto, o que facilitaria a internalização bacteriana, interferência com receptores de membrana e mecanismos de transporte e também competição por precursores (Rottem, 2003).

b. indução de formação de peróxido de hidrogênio e radicais superóxidos, que agem concomitantemente com moléculas endógenas tóxicas, induzindo estresse oxidativo no epitélio do hospedeiro (Avron, 1995).

c. indução de oxidação dos lipídeos e morte dos macrófagos no interior da placa (Higuchi, 2000)

Devido à alta capacidade de modulação do sistema imune do hospedeiro e sua presença em grande quantidade nas lesões ateroscleróticas, acredita-se em uma possível participação deste agente na formação e desenvolvimento dos aneurismas de aorta. 


\section{Objetivos}


O presente trabalho tem como objetivo verificar se agentes infecciosos podem estar relacionados ao desenvolvimento de aneurisma de aorta, estudando comparativamente fragmentos ateroscleróticos de aorta com e sem aneurisma, através da análise dos seguintes elementos:

a. Metaloproteinase -9 (MMP-9) e Inibidor tecidual da metaloproteinase - 1 (TIMP-1);

b. Receptores ativados por proliferadores de peroxissomos alfa (PPAR $\alpha$ ) e gama (PPAR $\mathrm{y})$;

c. Antígenos dos agentes infecciosos Chlamydophila pneumoniae e Mycoplasma pneumoniae. 
3. Materiais e Métodos 


\subsection{CASUÍSTICA}

O protocolo deste trabalho foi aprovado pela Comissão Científica do Instituto do Coração e pela Comissão de Ética em Pesquisa do Hospital das Clínicas da Universidade de São Paulo (SDC 2589/05/009), sendo dispensado o termo de consentimento livre e esclarecido (anexo 1).

A casuística do estudo foi composta por 28 fragmentos de aorta, divididos em dois grupos, pareados por sexo e idade:

- Grupo 1: constituído por 14 fragmentos de aorta abdominal, apresentando lesões ateroscleróticas graves, obtidos durante 0 procedimento de necropsia realizado no laboratório de Anatomia Patológica do Instituto do Coração. Para inclusão na casuística a principal causa de morte foi a aterosclerose grave ou suas complicações. O grupo constou de 10 indivíduos do sexo masculino e 4 do sexo feminino, com idade média de 70,3 $\pm 7,9$ anos

- Grupo 2: constituído por 14 fragmentos de aneurisma inespecífico de aorta, produto de correção cirúrgica realizadas no Instituto do Coração pela equipe do Prof. Dr. Noedir Stolf e no Hospital das Clínicas pela equipe do Prof. Dr. Erasmo Simão da Silva no período de setembro de 2004 a setembro de 2005. O grupo constou de 10 indivíduos do sexo masculino e 4 do sexo feminino, com idade média de 67,1 $\pm 8,2$ anos.

Os quadros 1 e 2 (anexos) mostram em detalhes os dados dos pacientes de G1 e G2. 


\subsection{MÉTODOS}

Para a realização do estudo comparativo entre fragmentos de aorta com aneurisma e fragmentos de aorta com aterosclerose grave não aneurismático foi necessária a utilização de material de diferentes origens, sendo os fragmentos com aneurisma derivados de ressecção cirúrgica e os com aterosclerose grave de necropsia. Os procedimentos de necropsia realizados no Laboratório de Anatomia Patológica do Instituto do Coração são realizados em até 12 horas após a determinação da morte do paciente. Este tempo entre a morte do paciente e a coleta do material não acarreta alterações drásticas no tecido como perda das estruturas normais das células e autólise do tecido. A diferença na origem das amostras utilizadas não implica em alterações significantes, que poderiam comprometer a qualidade deste estudo.

As amostras foram fixadas em formol salina, tamponado a $10 \%$, por no mínimo 12 horas foram seccionadas e processadas rotineiramente em processador automático de tecido (Leica, Heidelberg Alemanha) para posterior inclusão em parafina. Secções consecutivas de $5 \mu \mathrm{m}$ foram coradas pelo método de rotina hematoxilina / eosina $(H / E)$, hematoxilina férrica de Verhoeff (fibras elásticas) e Picrossirius (colágeno). Cortes subseqüentes foram submetidos às reações de imuno-histoquímica para a metaloproteinase - 9 (MMP-9), inibidor tecidual das metaloproteinases - 1 (TIMP-1) receptores ativados por proliferadores de peroxissomo alfa (PPAR 
$\alpha$ ) e gama (PPAR $\gamma$ ) e pesquisa dos agentes infecciosos Chlamydophila pneumoniae e Mycoplasma pneumoniae.

\subsubsection{Reação de Imuno-histoquímica}

Os cortes com $5 \mu \mathrm{m}$ de espessura, colocados em lâminas silanizadas, foram desparafinados em três banhos de xilol, três banhos de álcool 100\%, dois banhos de álcool 95\%, um banho de álcool 70\% e hidratados em água corrente. Após o processo de desparafinação, quando necessário, os sítios antigênicos foram recuperados de acordo com as recomendações dos fabricantes dos anticorpos primários (ver tabela 1).

Para o bloqueio da peroxidase endógena os tecidos foram incubados em 2 banhos de peróxido de hidrogênio a 3\% em PBS, por 10 minutos, em temperatura ambiente. Em seguida, para evitar ligações cruzadas com as demais proteínas presentes no tecido estudado, os cortes foram tratados com protein block serum free (DAKO; Carpinteria, CA) por 30 minutos a $37^{\circ} \mathrm{C}$. A incubação com o anticorpo primário específico (para diluição dos anticorpos, ver tabela 1 ) foi realizada a $4^{\circ} \mathrm{C}$, por no mínimo 18 horas. Após lavagem em PBS, os cortes foram incubados com o sistema de detecção mais apropriado (ver tabela abaixo) de acordo com as orientações do fabricante. Para revelação da reação, utilizou-se o kit DAB líquido (DAKO; Carpinteria, CA) segundo as orientações do fabricante, que produz um substrato da cor marrom caracterizando a positividade da imunomarcação. A contra-coloração foi realizada com hematoxilina de Harris. A seguir as 
lâminas foram montadas com lamínula, utilizando-se a resina entellan (Merck, Alemanha).

\subsubsection{Dupla marcação}

Para as reações de dupla marcação, inicialmente foi realizada uma reação de imunoperoxidase para PPAR $\alpha$ e $\mathrm{y}$ de acordo com o protocolo descrito acima, sem contra-coloração com a hematoxilina. Após revelação com o DAB, as lâminas foram lavadas em tampão PBS e incubadas com o anticorpo anti CD68 por 2 horas em estufa $37^{\circ} \mathrm{C}$. Para detecção do complexo antígeno-anticorpo utilizou-se estreptoavidina conjugada com fosfatase alcalina (Amershan, UK) diluída 1:100 por 1 hora a $37^{\circ} \mathrm{C}$. A reação foi revelada utilizando-se o substrato cromógeno New fuchsin (DAKO; Carpinteria, CA), contra-corada com hematoxilina Harris e montada com meio aquoso (Biomeda; Foster City, CA). 
Tabela 1: Anticorpos e métodos de recuperação utilizados para as reações de imunohistoquímica

\begin{tabular}{|c|c|c|c|c|}
\hline Anticorpo & Clone & Recuperação antigênica & Diluição & Sistema de detecçãoo \\
\hline anti MMP-9 ${ }^{1}$ & policlonal de coelho & Sem recuperação & $1: 150$ & Histostain $^{2}$ \\
\hline anti TIMP-1 ${ }^{1}$ & 102D1 & Pascal, tampão Tris/EDTA, pH=9,0 & $1: 600$ & Histostain $^{2}$ \\
\hline anti PPAR $\alpha(C-20)^{3}$ & policlonal de coelho & MO 20 minutos, tampão citrato $\mathrm{pH}=6,0$ & $1: 100$ & Histostain $^{2}$ \\
\hline anti PPAR $\gamma^{3}$ & $\mathrm{E}-8$ & MO 20 minutos, tampão citrato $\mathrm{pH}=6,0$ & $1: 20$ & Histostain $^{2}$ \\
\hline anti Chlamydophila pneumoniae ${ }^{4}$ & RR402 & B-M $95^{\circ} \mathrm{C}$, tampão Tris/EDTA, $\mathrm{pH}=9,0$ & $1: 10$ & Envision ${ }^{4}$ \\
\hline anti Mycoplasma pneumoniae ${ }^{5}$ & M2110181 & B-M $95^{\circ} \mathrm{C}$, tampão Tris/EDTA, $\mathrm{pH}=9,0$ & $1: 100$ & Envision ${ }^{4}$ \\
\hline anti CD68 ${ }^{4}$ & KP1 & MO 20 minutos, tampão citrato $\mathrm{pH}=6,0$ & $1: 500$ & Estreptoavidina $^{6}+\mathrm{FAL}$ \\
\hline
\end{tabular}

\section{Legenda}

1- Neo Markers - Fremont, EUA; 2- Zymed - São Francisco, EUA; 3 - Santa Cruz Biotechnology - Santa Cruz, EUA;

4- Dako Cytomation - Carpinteria, EUA; 5 - Fizgerald Industries International, Inc. - Concord, EUA; 6- Amersham - Buckinghamshire, UK.

MO = microondas; $B M=$ banho - maria, $F A L=$ fosfatase alcalina 


\subsubsection{Análise das reações}

Utilizando-se os cortes histológicos corados pelo método histoquímico de Verhoeff, que delimita bem as lâminas elásticas interna e externa da parede das artérias, as espessuras das três camadas da aorta foram determinadas em $\mu \mathrm{m}$, utilizando-se o sistema de análise de imagens Quantimet 500 (Leica, Benfheim, Alemanha). Utilizou-se segmentos de reta perpendiculares à luz do vaso da superfície endotelial até a lâmina elástica interna, para medir a íntima, entre as lâminas elásticas interna e externa para medir a camada média, e entre a lâmina elástica externa e a superfície da camada adventícia para medir esta ultima. As espessuras foram analisadas em três regiões distintas do corte, adotando-se os valores médios para as análises estatísticas.

A inflamação presente na camada adventícia foi semiquantificada pela coloração H/E por dois observadores individuais, que em caso de discordância, entravam em acordo após visualização simultânea das lâminas. Foram utilizados os seguintes escores: 0 (ausência de células inflamatórias), 1 (presença discreta de células inflamatórias), 2 (moderada), 3 (intenso). Para obtenção de valores representativos de todo o corte, as reações de Picrossirius e a positividade das reações de imunoperoxidase foram quantificadas na objetiva $20 \mathrm{X}$ em três regiões distintas, obtidas traçando-se três retas perpendiculares ao comprimento do segmento de

aorta em estudo. A quantificação foi realizada apenas em campos cheios, individualizando o tecido adiposo periadventicial (apenas para as reações de imuno-histoquímica), a camada adventícia, a média e a íntima, utilizando-se 
o sistema de detecção por cor do analisador de imagens Quantimet 500. Os valores médios em porcentagem de área (\% área) foram utilizados para as análises estatísticas.

\subsubsection{Análise estatística}

Os dados obtidos foram analisados utilizando-se 0 software SigmaStat v.2.0 (SPSS Inc., Chicago, EUA). Inicialmente, foi feita a análise descritiva das variáveis para resumir os dados através de um valor mínimo, máximo, média, mediana e desvio padrão. A normalidade dos dados foi analisada através dos testes de Kolmogorv-Smirnov e Shapiro-Wilk. Os grupos foram comparados em relação às demais variáveis por meio dos testes t-Student ou Man-Whitney de acordo com a sua distribuição de normalidade. Para averiguar as correlações entre as variáveis analisadas foram aplicados os testes de correlação de Pearson ou de Spearman, adotando-se nível de significância de p $\leq 0,05$. 
4. Resultados 


\subsection{ANÁLISE HISTOLÓGICA DESCRITIVA DAS AORTAS}

\subsubsection{Fragmentos ateroscleróticos sem aneurisma}

A análise dos fragmentos de aorta sem aneurisma apresentou características histológicas compatíveis com lesões ateroscleróticas graves.

$\mathrm{Na}$ camada adventícia foi observada uma discreta inflamação, localizada preferencialmente nas regiões periféricas da camada, e também na região perivascular. $\mathrm{O}$ tecido adiposo periadventicial esteve presente em quase todos os casos, apresentando um pobre infiltrado inflamatório (figura 1A). Os vasos que compõem o vasa vasorum apresentaram-se em sua maioria com espessamento intimal (figura 2A).

A camada média apresentou-se irregular, com variações desde espessuras normais ou muito diminuídas no mesmo corte histológico (figura 3A), além de variável quantidade de células inflamatórias.

Espessamento da camada íntima esteve presente em todos os casos, caracterizado por fibrose intensa e difusa envolvendo frequentemente núcleos gordurosos necróticos exibindo imagens negativas de cristal de colesterol (figura 4A). Outros achados comuns foram: calcificação de intensidade moderada, rotura da placa e presença de trombos. Os locais com grande quantidade de gordura apresentaram-se circundados por células inflamatórias, por vezes associadas a vasos neoformados. 


\subsubsection{Fragmentos ateroscleróticos com aneurisma}

Os fragmentos de aorta com aneurisma mostraram intensa distorção arquitetural da parede vascular.

A camada adventícia esteve espessada evidenciando fibras colágenas grossas, caracterizando uma fibrose cicatricial. Observou-se intenso infiltrado inflamatório, geralmente concentrado nas extremidades da camada, onde há contato com o tecido adiposo periadventicial e a região de transição para a camada média. O tecido adiposo periadventicial tinha grande infiltração por células inflamatórias (figura 1B), que estavam também concentradas na região perivascular do vasa vasorum que com freqüência mostrava-se congesto (figura 2B). Além disso, foi possível verificar neoformação vascular, não apenas na camada adventícia como também na camada média (figura 5).

A camada média apresentou-se invariavelmente afilada, com perda de células musculares lisas e destruição das fibras elásticas, notando-se em alguns casos zonas de ausência completa desta túnica (figura 3B).

Espessamento intimal foi observado em todos os casos, com presença ou não de placas gordurosas e imagem negativa dos cristais de colesterol. Além disso, foram encontradas calcificação e células inflamatórias na periferia da lesão, em intensidade variável, e fibrose moderada. Ulceração foi freqüentemente observada e trombos encontrados, em freqüência e extensão variáveis (figura 4B). 


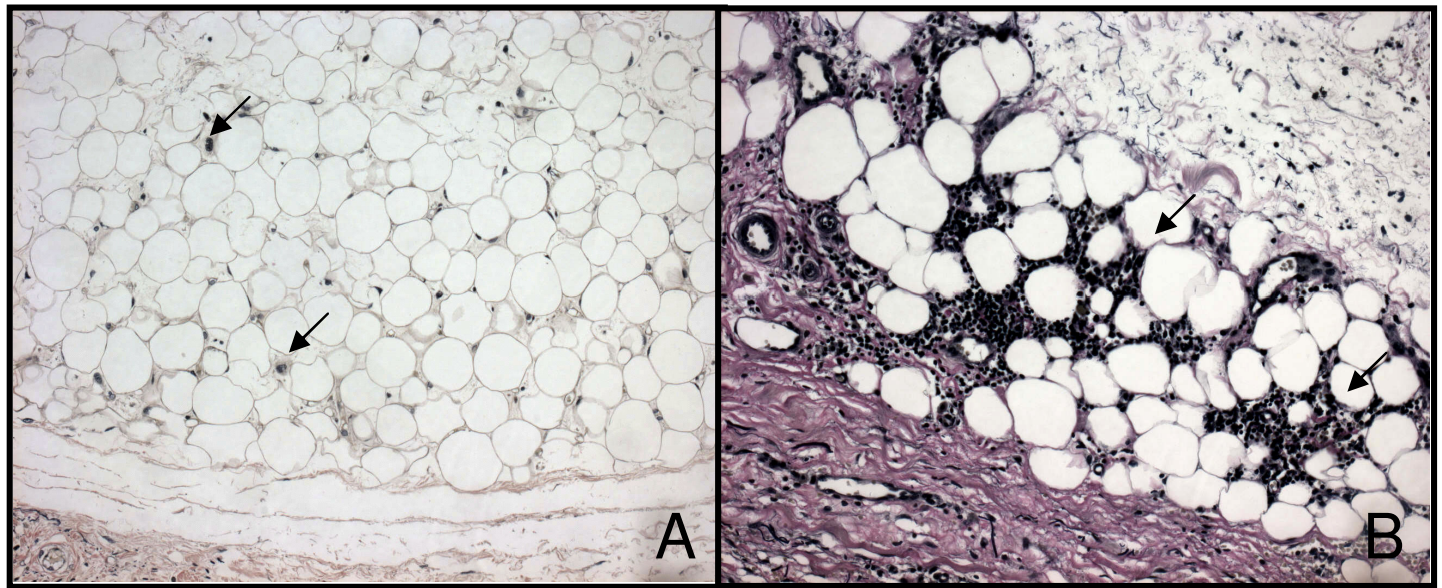

Figura 1 - Aspecto histológico do tecido adiposo periadventicial em G1 (1A) e G2 (1B), apresentando intensa inflamação em meio às células adiposas (setas). Coloração de Verhoeff, aumento original 20x.

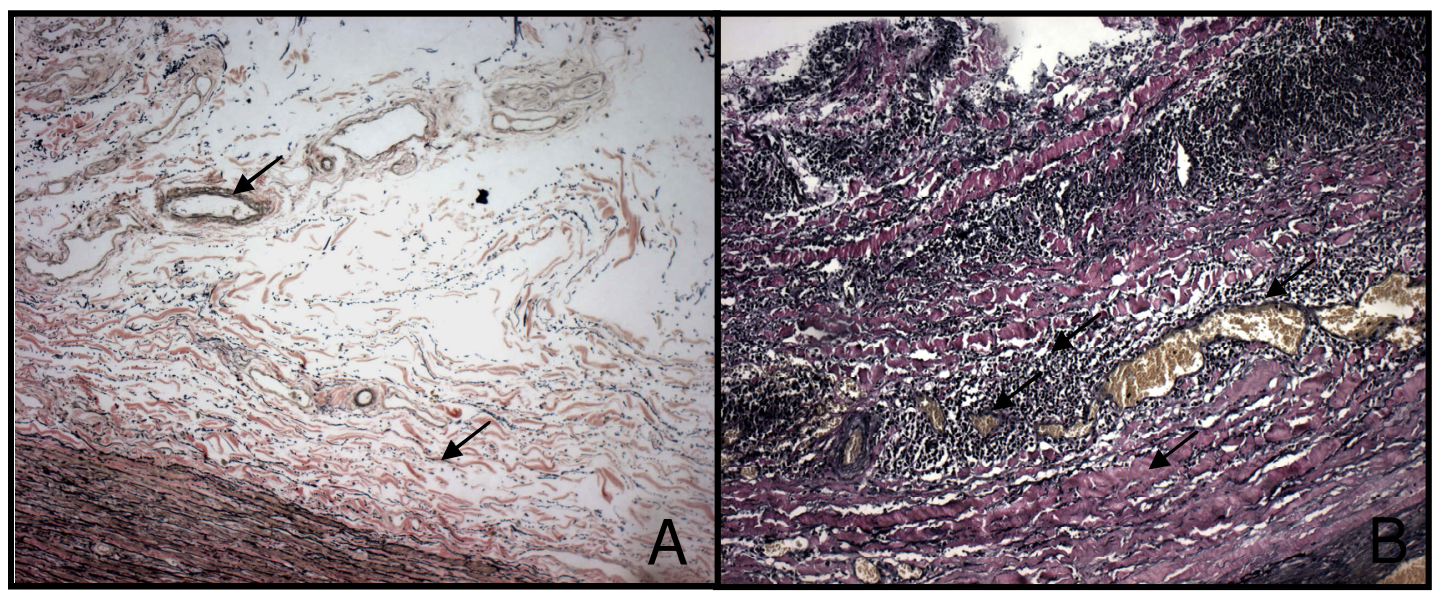

Figura 2 - Aspecto histológico da adventícia. 2A: G1 exibindo poucas célula inflamatórias, espessamento intimal do vasa vasorum. 2B: G2 exibindo intenso infiltrado inflamatório, principalmente na região do vasa vasorum. Observar espessamento da adventícia de G2 em relação a G1. Coloração de Verhoeff, aumento original $10 x$.

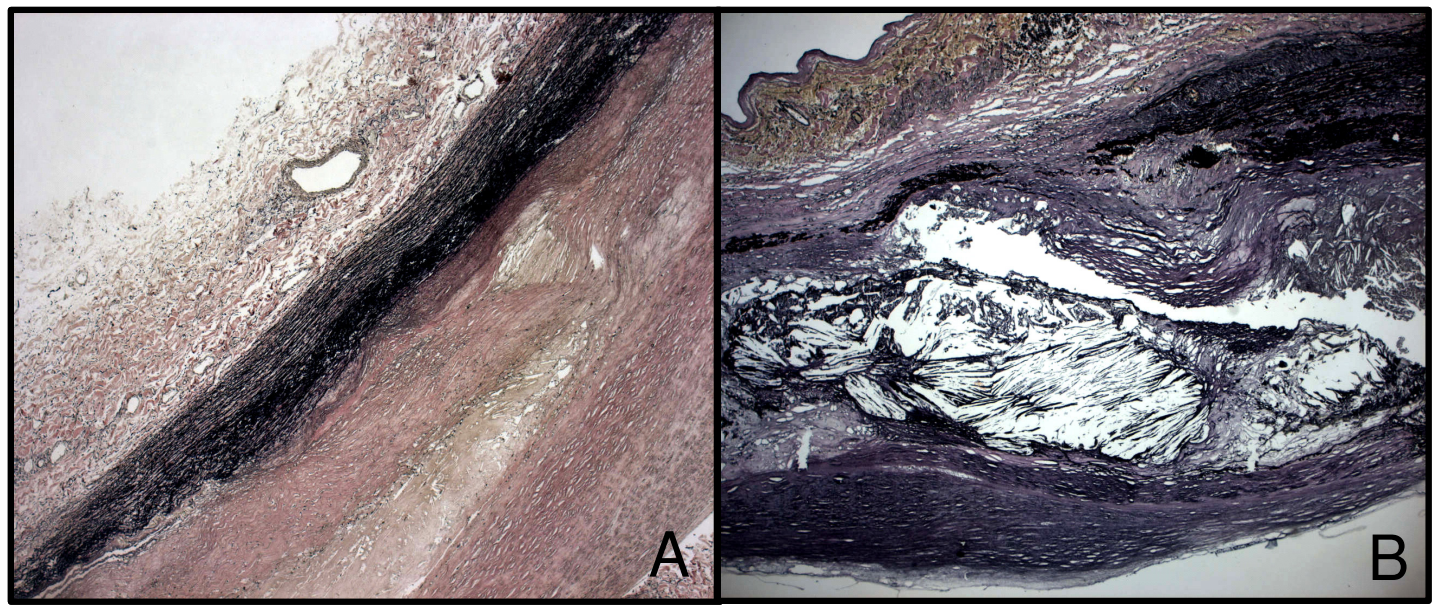

Figura 3 - Visão panorâmica da histologia dos fragmentos de aorta em $3 \mathrm{~A}$ fragmento aterosclerótico e 3B fragmento aneurismático, com ênfase ao afilamento da média. Coloração de Verhoeff, aumento original 5x. 


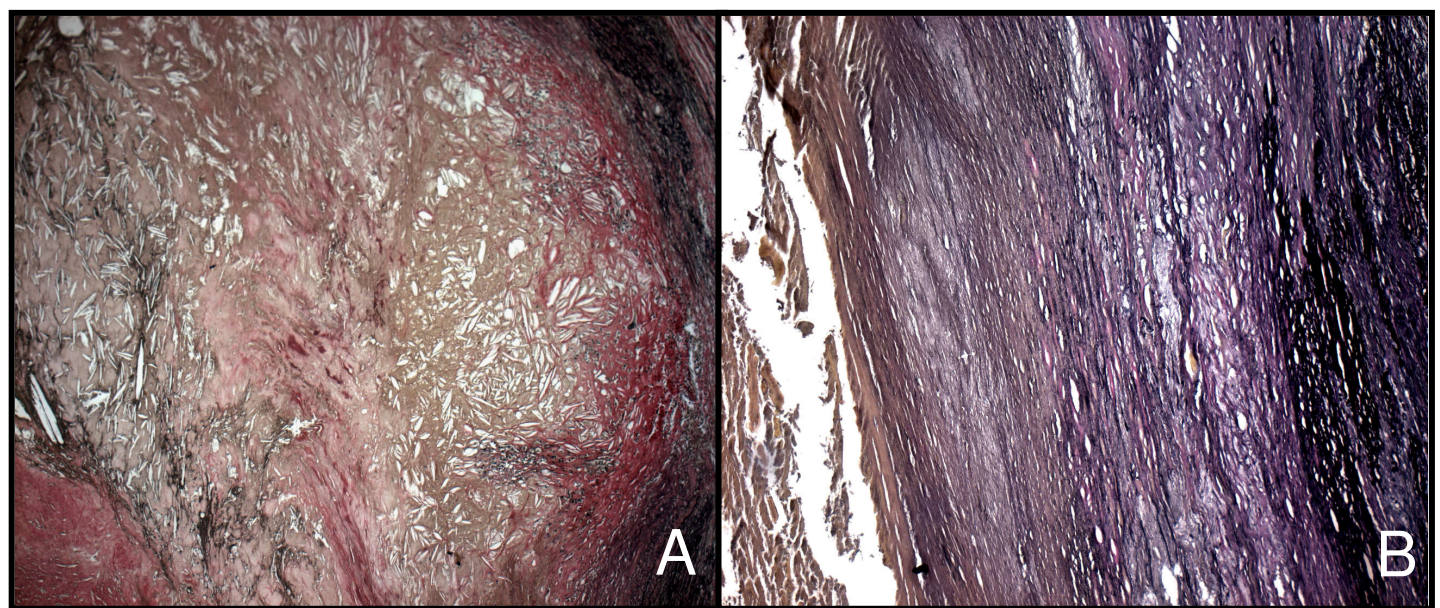

Figura 4 - Aspecto histológico da camada íntima. 4A: G1 exibindo placa com grande núcleo lipídico e capa de fibrose. 4B: G2 com placas sem capa de fibrose trombos na superfície. Coloração de Verhoeff, aumento original de $5 x$ em $A$ e $10 x$ em $B$.

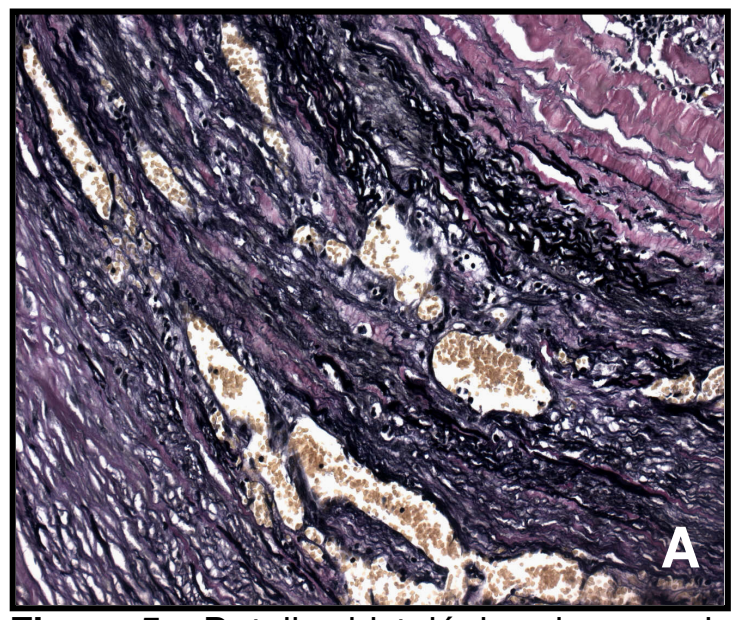

Figura 5 - Detalhe histológico da camada média em fragmento de $\mathrm{G} 2$, enfatizando a neoformação vascular. Aumento original $20 x$. 


\subsection{ANÁLISE DAS MEDIDAS DE ESPESSURAS DAS CAMADAS DA PAREDE VASCULAR}

As espessuras obtidas de cada camada da parede vascular estão representadas no gráfico da figura 6 e demonstradas na tabela 2.

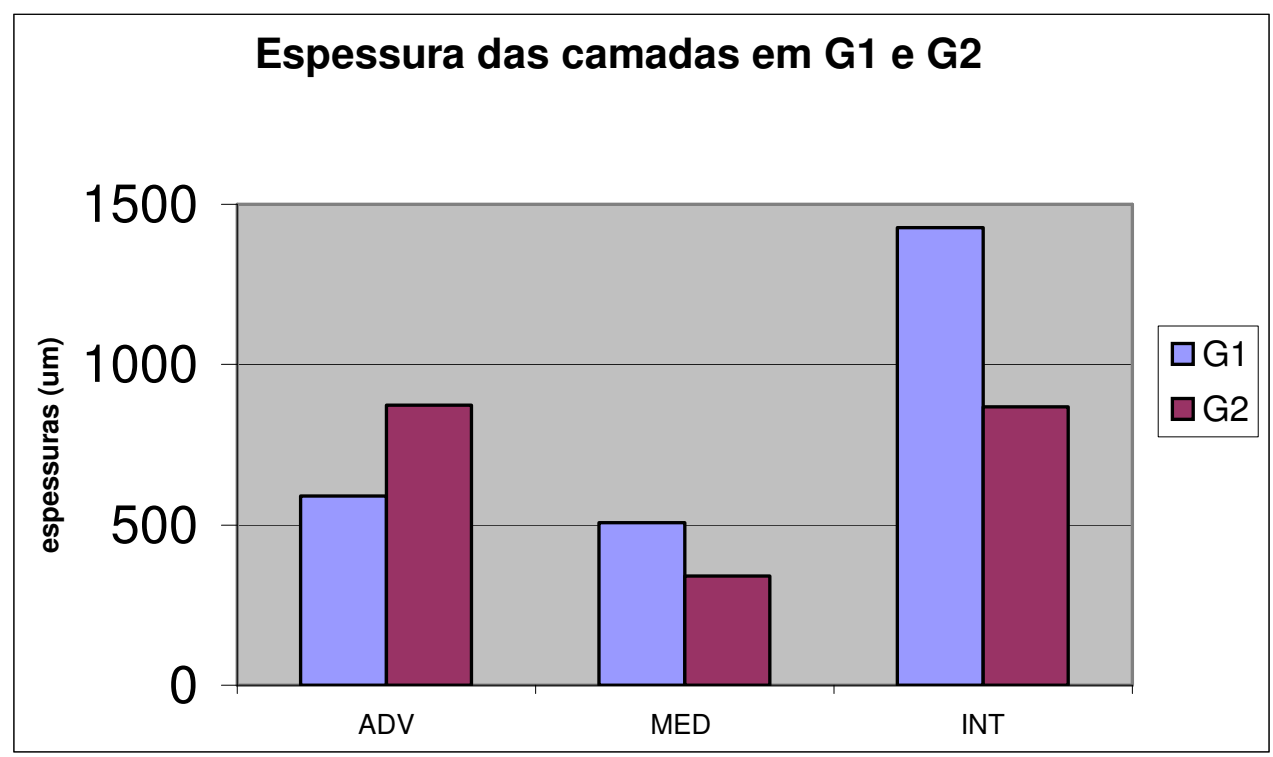

Figura 6 - Análise das espessuras, das camadas adventícia (ADV), média (MED) e íntima (INT) em G1 e G2

Os valores médios (tabela 2) da espessura da camada adventícia nos fragmentos com aneurisma estiveram maiores em relação aos com aterosclerose $(p=0,02)$, no entanto não houve diferença na espessura da camada média $(p=0,46)$. A camada íntima apresentou-se muito mais espessada no grupo com aterosclerose $(p<0,001)$, que no grupo com aneurisma. 
TABELA 2 - Média e desvio padrão da espessura em $\mu \mathrm{m}$ da adventícia, média e íntima em G1 e G2

\begin{tabular}{cccc}
\hline Camadas & G1 & G2 & p \\
\hline ADV & $573,66 \pm 154,67$ & $843,61 \pm 393,94$ & $0,02^{\dagger}$ \\
MED & $474,11 \pm 201,36$ & $460,27 \pm 356,78$ & $0,46^{\dagger}$ \\
INT & $1496,99 \pm 522,54$ & $844,90 \pm 453,96$ & $0,00^{\dagger}$ \\
\hline
\end{tabular}

ADV - camada adventícia; MED - camada média; INT - camada íntima

† teste $\mathrm{t}$

\subsection{ANÁLISE DA QUANTIDADE DE COLÁGENO NA PAREDE VASCULAR}

A análise histológica dos fragmentos de aorta revelou diferenças importantes entre os dois grupos estudados. A camada adventícia apresentou-se espessada com aumento da fibrose no grupo com aneurisma. Para confirmação deste achado foi realizada a quantificação do colágeno através da coloração histoquímica Picrossirius (figura 7). Os dados obtidos em porcentagem (\%) de área estão demonstrados na tabela 3.

Tabela 3: Média e desvio padrão da quantidade de colágeno (\% área) na parede vascular em G1 e G2

\begin{tabular}{cccc}
\hline camadas & G1 & G2 & $\mathbf{p}$ \\
\hline ADV & $10,86 \pm 5,48$ & $25,56 \pm 10,49$ & $<0,001^{\dagger}$ \\
MED & $13,14 \pm 9,10$ & $10,98 \pm 5,34$ & $0,50^{\dagger}$ \\
INT & $27,13 \pm 9,05$ & $28,29 \pm 13,72$ & $0,80^{\dagger}$ \\
\hline
\end{tabular}

${ }^{\dagger}$ teste $\mathrm{t}$ 
A quantidade de colágeno da camada adventícia dos fragmentos com aneurisma está aumentada em relação aos fragmentos com aterosclerose, apresentando uma diferença altamente significante $(p<0,001)$. Por outro lado, as camadas média e íntima não apresentaram diferenças entre os dois grupos ( $p=0,50$ e $p=0,80$, respectivamente).

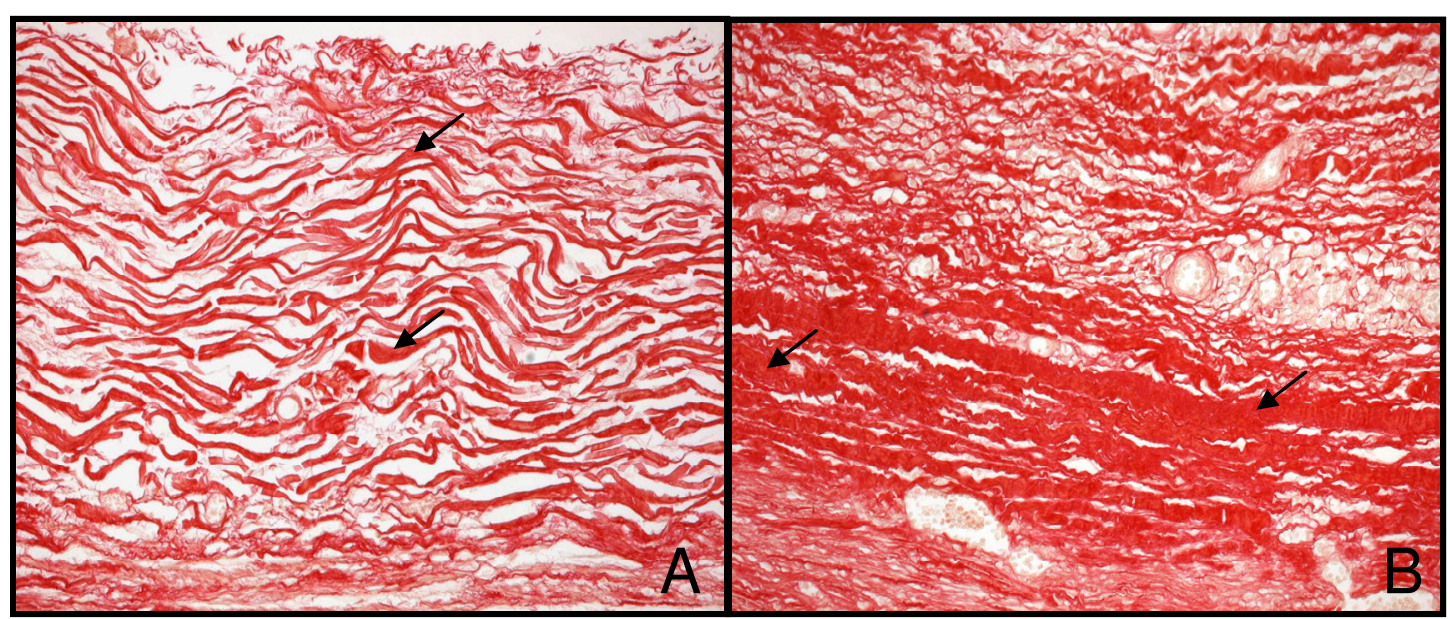

Figura 7 - Aspecto histológico da camada adventícia. Observar diferença no padrão das fibras de colágeno em A (Gl) e em B (GIl). Coloração Picrossirius, aumento original 20x.

\subsection{ANÁLISE DOS DADOS SEMIQUANTITATIVOS DA INFLAMAÇÃO NA ADVENTÍCIA}

A inflamação presente na camada adventícia dos fragmentos com aterosclerose foi considerada de leve a moderada, enquanto que nos fragmentos com aneurisma mostrou-se intensa em quase todos os casos (ver figura 2B). A análise estatística apresentou diferença significante entre os dois grupos $(p=0,02)$ (figura 8$)$. 


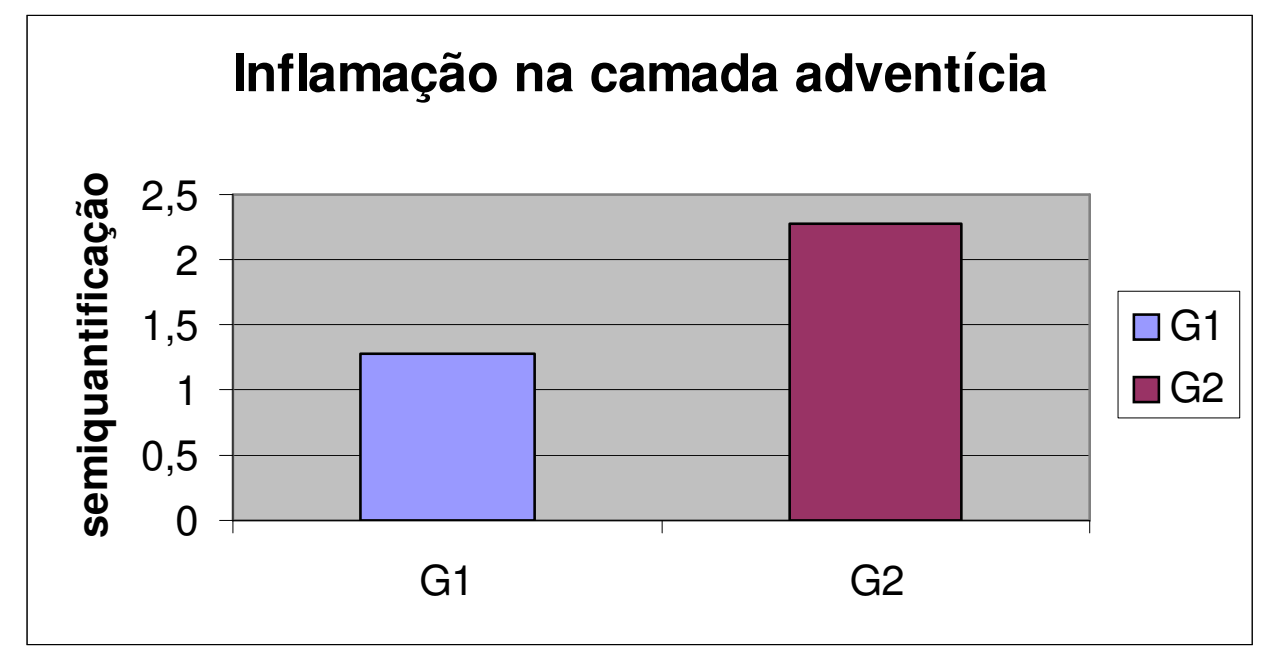

Figura 8 - Semiquantificação da inflamação na camada adventícia

A semiquantificação da inflamação revelou grande número de células inflamatórias infiltradas no tecido adiposo periadventicial. Frente a esses achados incluímos esse tecido de forma individual na avaliação quantitativa.

\subsection{ANÁLISE DAS AVALIAÇÕES QUANTITATIVAS DE ANTíGENOS NAS DIFERENTES CAMADAS DA PAREDE VASCULAR}

\subsubsection{MMP-9 e TIMP-1}

Os valores médios em \% de área obtidos através da quantificação das reações de imuno-histoquímica para MMP-9 (figura 9) e para TIMP-1 (figura 10) nas diferentes regiões da parede vascular estão apresentados nas tabelas 4 e 5 .

A expressão da MMP-9 no tecido adiposo periadventicial (TAP) e na camada adventícia foi maior no grupo com aneurisma, entretanto diferença significativa foi observada somente no tecido adiposo $(p=0,04)$. Por outro 
lado, na camada média e na íntima houve positividade importante, porem sem diferença estatística entre os dois grupos.

Tabela 4 - Expressão de MMP-9 na parede vascular e comparação entre G1 e G2

\begin{tabular}{ccccc}
\hline MMP-9 & TAP & ADV & MED & INT \\
\hline G1 & $0,74 \pm 0,84$ & $1,17 \pm 1,6$ & $1,66 \pm 3,80$ & $4,16 \pm 5,42$ \\
G2 & $1,70 \pm 1,23$ & $2,10 \pm 1,87$ & $0,43 \pm 0,51$ & $2,91 \pm 1,91$ \\
p & $\mathbf{p}=\mathbf{0 , 0 4 ^ { \dagger }}$ & $\mathrm{p}=0,15^{\ddagger}$ & $\mathrm{p}=0,83^{\ddagger}$ & $\mathrm{p}=0,43^{\dagger}$
\end{tabular}

TAP- tecido adiposo periadventicial

$\dagger$ teste $t$

‡ Mann Whitney

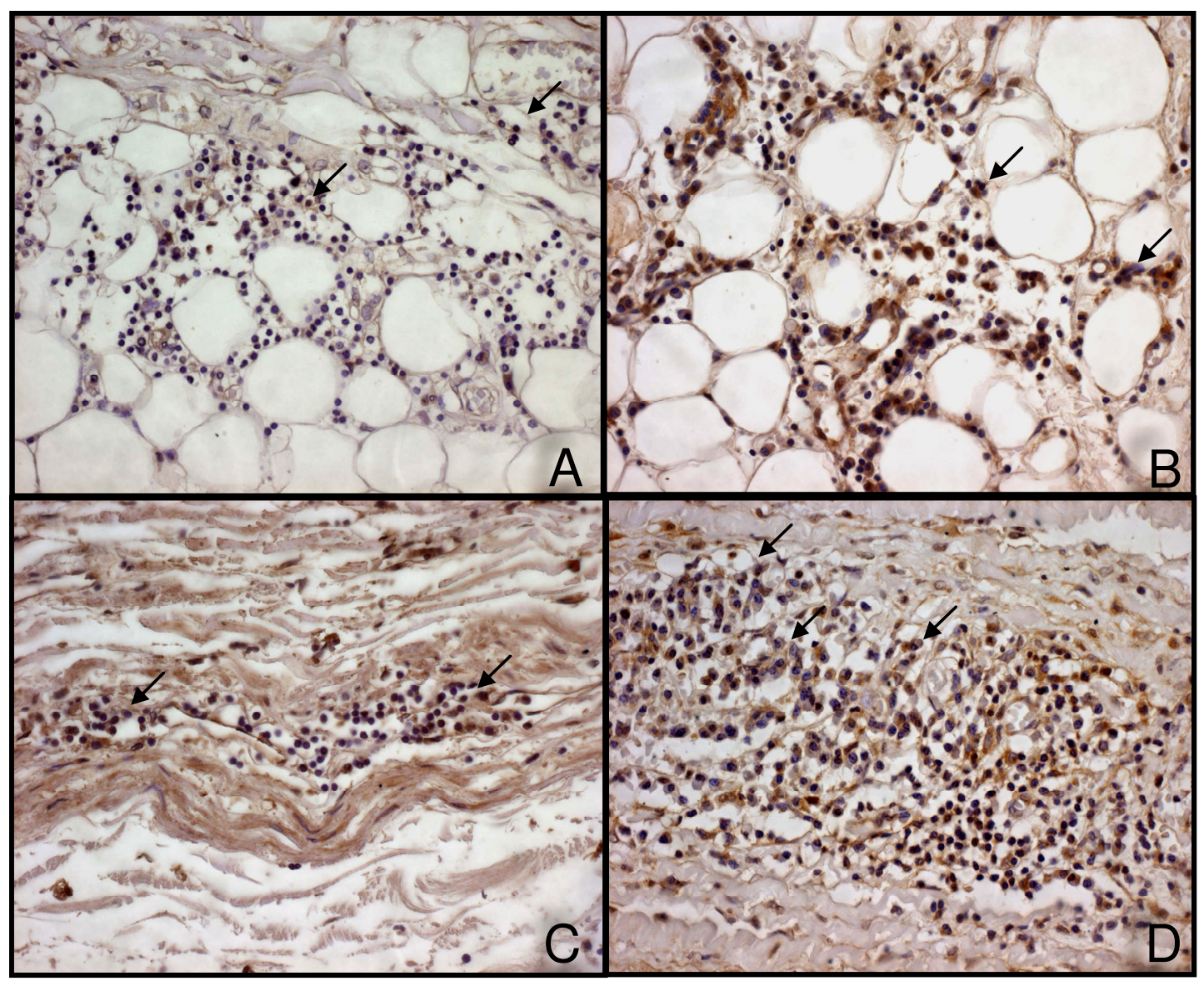

Figura 9 - Imuno-histoquímica apresentando células positivas para MMP-9. A tecido adiposo periadventicial de $\mathrm{G} 1$; $\mathbf{B}$ tecido adiposo periadventicial de G2; C adventícia de G1; D adventícia de G2. Aumento original 40x . 
O inibidor tecidual da MMP-9 (TIMP-1) esteve mais expresso no grupo com aneurisma em todas as camadas da parede vascular, apresentado diferença estatística no tecido adiposo $(p=0,03)$ e na camada adventícia $(p=0,04)$.

Tabela 5 - Expressão de TIMP-1 na parede vascular e comparação entre G1 e G2

\begin{tabular}{|c|c|c|c|c|}
\hline TIMP-1 & TAP & ADV & MED & INT \\
\hline G1 & $0,26 \pm 0,34$ & $0,4 \pm 0,44$ & $0,05 \pm 0,07$ & $1,25 \pm 1,67$ \\
\hline G2 & $1,79 \pm 2,60$ & $2,18 \pm 2,89$ & $0,05 \pm 0,06$ & $2,36 \pm 3,28$ \\
\hline $\mathbf{p}$ & $0,03^{\ddagger}$ & $0,04^{\ddagger}$ & $0,10^{\ddagger}$ & $0,33^{\dagger}$ \\
\hline
\end{tabular}

${ }^{\dagger}$ teste t

‡ Mann Whitney 


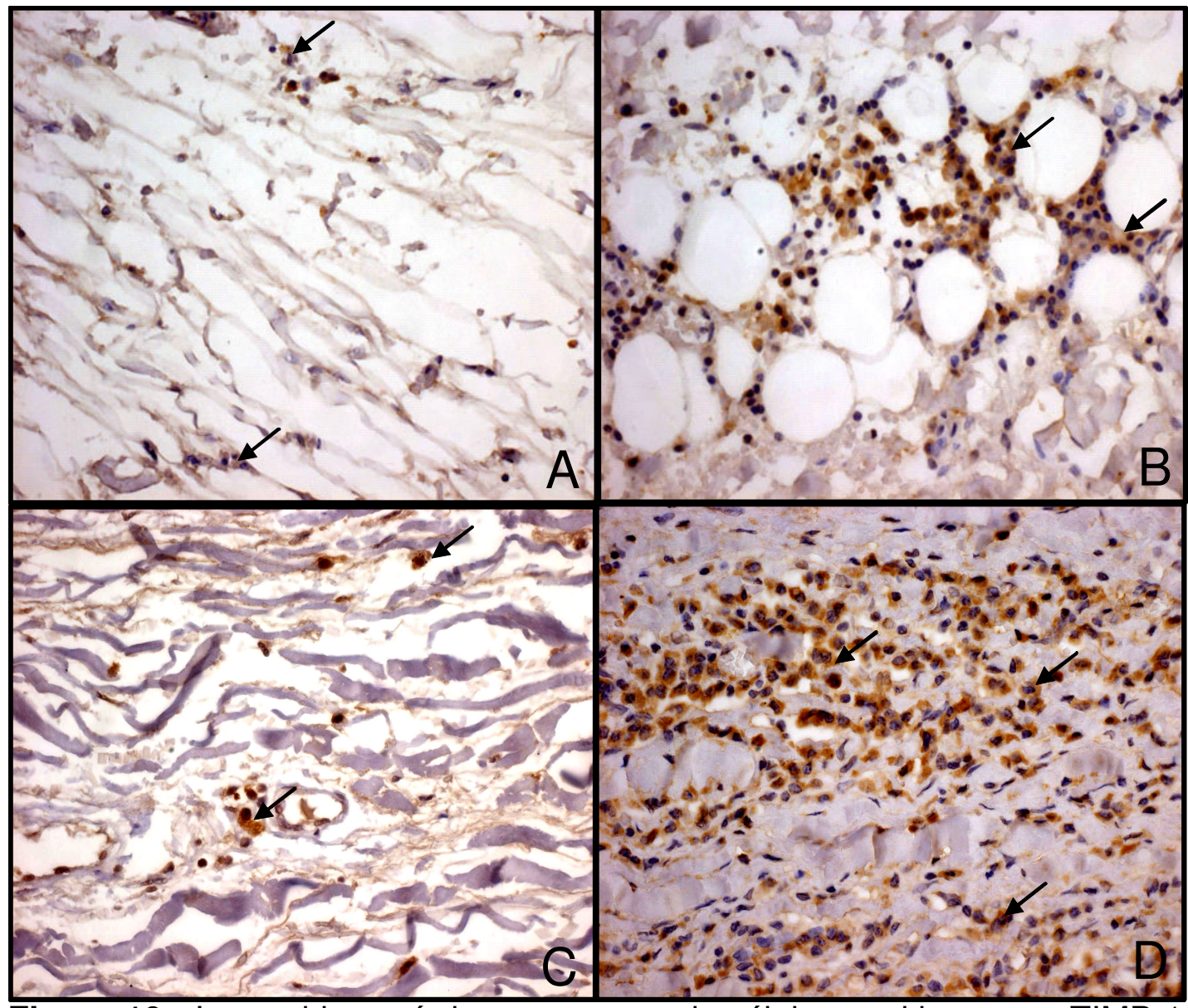

Figura 10 - Imuno-histoquímica apresentando células positivas para TIMP-1. A tecido adiposo periadventicial de G1; $B$ tecido adiposo periadventicial de G2; $\mathbf{C}$ adventícia de G1; D adventícia de G2. Aumento original 40x .

\subsubsection{PPARs}

Os valores médios em \% de área obtidos através da quantificação das reações de imuno-histoquímica para PPAR $\alpha$ (figura 11) e para PPAR $\gamma$ (figuras 12) nas diferentes regiões da parede vascular estão apresentados nas tabelas 6 e 7. PPAR $\alpha$ esteve expresso em todas as camadas da parede vascular. A imunopositividade foi observada em raros núcleos e principalmente no citoplasma das células inflamatórias presentes na adventícia, células endoteliais, e células musculares lisas. A expressão do PPAR $\alpha$ foi maior no tecido adiposo $(p<0,001)$ e na camada adventícia 
$(p<0,001)$ dos fragmentos de aorta com aneurisma. Por outro lado, nas camadas média e íntima sua expressão foi maior nos fragmentos com aterosclerose, mas sem diferença significante.

Tabela 6 - Expressão de PPAR $\alpha$ na parede vascular e comparação entre G1 e G2

\begin{tabular}{|c|c|c|c|c|}
\hline PPAR $\alpha$ & TAP & ADV & MED & INT \\
\hline G1 & $0,59 \pm 0,39$ & $0,91 \pm 0,58$ & $5,63 \pm 4,14$ & $2,78 \pm 1,85$ \\
\hline G2 & $2,00 \pm 1,05$ & $3,41 \pm 2,06$ & $3,58 \pm 3,87$ & $2,11 \pm 1,68$ \\
\hline$p$ & $p<0,001^{\ddagger}$ & $p<0,001^{\ddagger}$ & $\mathrm{p}=0,20^{\dagger}$ & $\mathrm{p}=0,32^{\dagger}$ \\
\hline
\end{tabular}




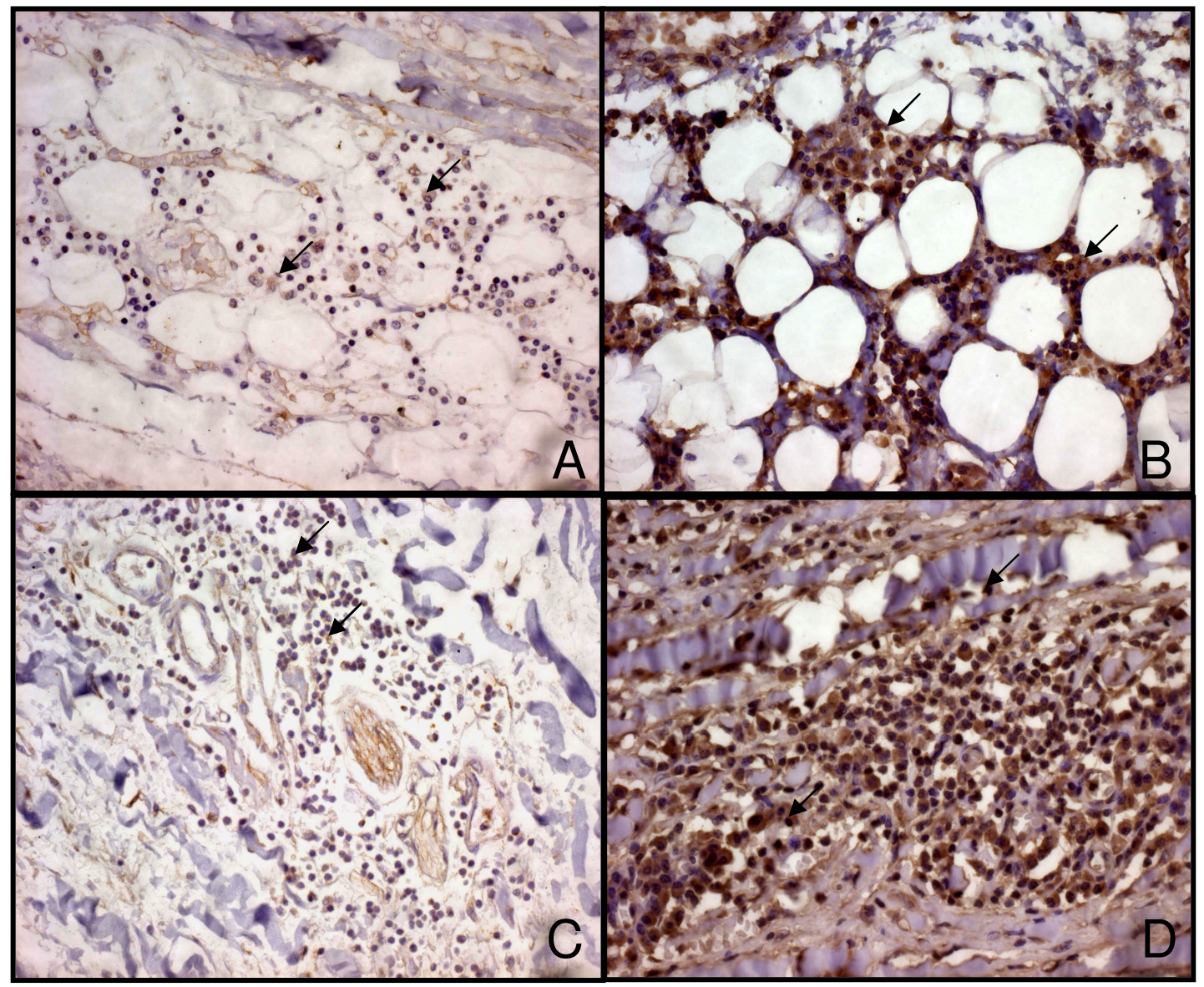

Figura 11: Imuno-histoquímica apresentando células positivas para PPAR $\alpha$. A tecido adiposo periadventicial de $\mathrm{G} 1$; $B$ tecido adiposo periadventicial de G2; C adventícia de G1; D adventícia de G2. Aumento original, 40x

A expressão de PPAR $\gamma$ foi observada nas três camadas da parede vascular com imunomarcação positiva principalmente no citoplasma das células inflamatórias, células endoteliais e células musculares lisas. A expressão do PPAR $\gamma$ no grupo com aneurisma foi maior em praticamente todas as camadas, entretanto em nenhuma delas houve diferença estatística significante. 
Tabela 7 - Expressão de PPAR $\gamma$ na parede vascular e comparação entre G1 e G2

\begin{tabular}{|c|c|c|c|c|}
\hline PPAR $\gamma$ & TAP & ADV & MED & INT \\
\hline G1 & $0,57 \pm 0,61$ & $0,42 \pm 0,52$ & $0,24 \pm 0,26$ & $1,48 \pm 1,92$ \\
\hline G2 & $0,75 \pm 0,99$ & $1,47 \pm 3,01$ & $0,50 \pm 0,75$ & $0,49 \pm 0,49$ \\
\hline $\mathbf{p}$ & $\mathrm{p}=0,80^{\ddagger}$ & $\mathrm{p}=0,76^{\ddagger}$ & $\mathrm{p}=1,00^{\ddagger}$ & $\mathrm{p}=0,22^{\ddagger}$ \\
\hline
\end{tabular}

${ }^{\ddagger}$ Mann Whitney

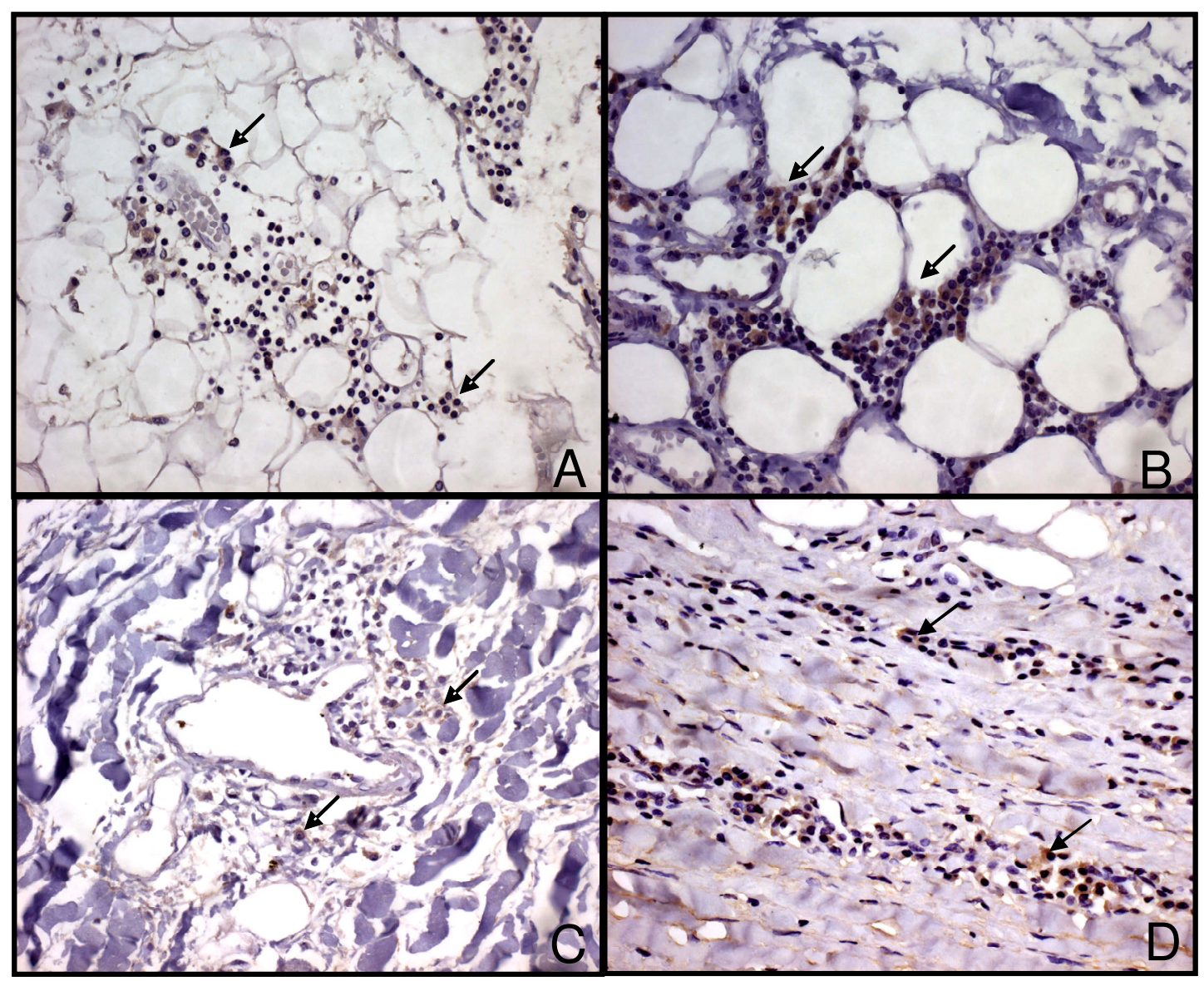

Figura 12 - Imuno-histoquímica apresentando células positivas para PPAR Y. A tecido adiposo periadventicial de $\mathbf{G 1}$; $\mathbf{B}$ tecido adiposo periadventicial de G2; $\mathbf{C}$ adventícia de G1; D adventícia de G2. Aumento original, 40x. 


\subsubsection{Dupla marcação para PPARs e macrófagos}

As reações de dupla marcação foram realizadas em apenas três casos do grupo com aneurisma para verificar a expressão dos PPARs nas células CD68 (macrófagos).

A dupla imunomarcação para PPAR $\alpha$ (figura 13A) mostrou um grande número de células com citoplasma duplamente positivo. Outros tipos celulares, como células musculares lisas e células endoteliais estiveram positivas para PPAR $\alpha$. Raros macrófagos apresentaram marcação exclusiva para CD68.

Por outro lado, a dupla marcação para PPAR $\gamma$ (figura 13B) e macrófagos apresentou um número menor de células duplamente marcada comparativamente à dupla marcação para o PPAR $\alpha$. Assim como nas reações individuais, o PPAR $\gamma$ esteve positivo em células inflamatórias, células endoteliais e células musculares lisas. Entretanto, foi observado um grande número de macrófagos imunomarcados somente para CD68.

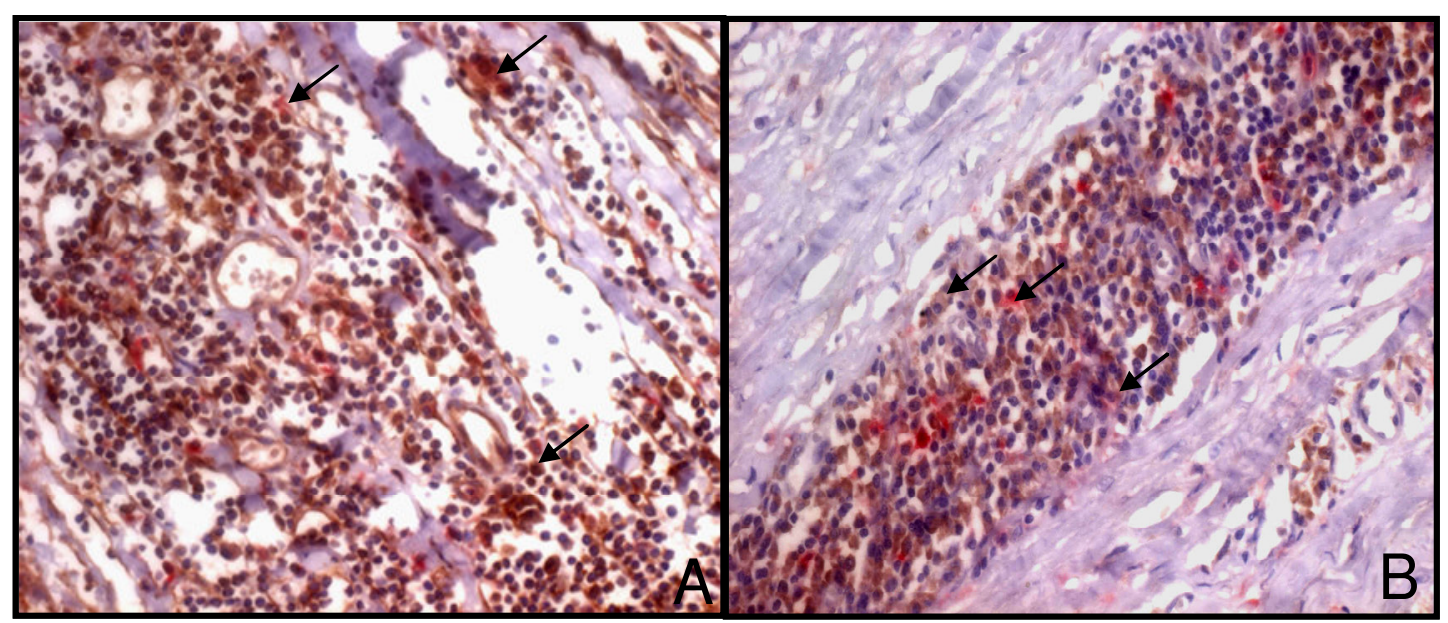

Figura 13 - Dupla imunomarcação para CD68 e PPAR $\alpha(A)$ e PPAR $\gamma(B)$. Observar presença de células duplamente marcadas e marcadas individualmente. Aumento original, 40x. 


\subsubsection{Agentes infecciosos: Chlamydophila pneumoniae e}

\section{Mycoplasma pneumoniae}

Os valores médios em \% de área obtidos através da quantificação das reações de imuno-histoquímica para Chlamydophila pneumoniae (figura 14) e para Mycoplasma pneumoniae (figura 15) nas diferentes regiões da parede vascular estão apresentados nas tabelas 8 e 9 .

Antígenos de Chlamydophila pneumoniae e Mycoplasma pneumoniae estiveram presentes em todas as camadas da parede vascular de ambos os grupos. Antígenos da Chlamydophila pneumoniae estiveram aumentados de forma significante no tecido adiposo periadventicial $(p=0,02)$ e na camada adventícia $(p=0,002)$ do grupo 2 comparado ao 1 .

Tabela 8 - Média dos valores de \% de área ocupada por Chlamydophila pneumoniae na parede vascular em G1 e G2 e comparação entre os grupos

\begin{tabular}{ccccc}
\hline CP & TAP & ADV & MED & INT \\
\hline G1 & $0,72 \pm 0,98$ & $0,54 \pm 0,52$ & $0,55 \pm 0,70$ & $1,98 \pm 1,55$ \\
$\mathbf{G 2}$ & $1,80 \pm 1,53$ & $2,63 \pm 3,70$ & $0,39 \pm 0,52$ & $3,10 \pm 2,27$ \\
$\mathbf{p}$ & $\mathbf{p}=\mathbf{0 , 0 2 ^ { \ddagger }}$ & $\mathbf{p}=\mathbf{0 , 0 0 2 ^ { \ddagger }}$ & $\mathrm{p}=0,96^{\ddagger}$ & $\mathrm{p}=0,14^{\dagger}$ \\
\hline
\end{tabular}

CP - Chlamydophila pneumoniae

${ }^{\dagger}$ teste $t$

‡ Mann Whitney 


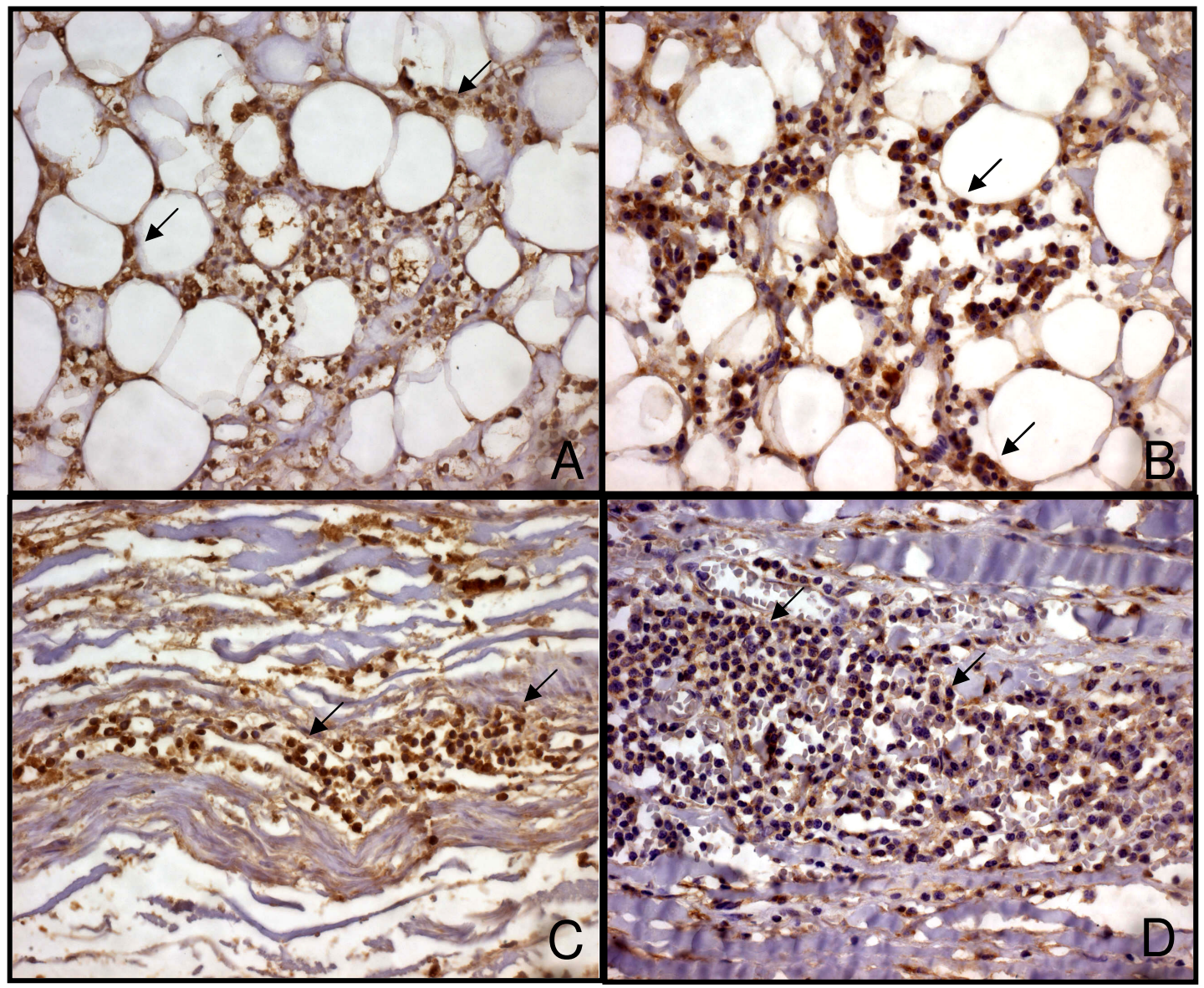

Figura 14 - Imuno-histoquímica apresentando células positivas para Chlamydophila pneumoniae. A tecido adiposo periadventicial de G1; B tecido adiposo periadventicial de G2; $\mathbf{C}$ adventícia de G1; $\mathbf{D}$ adventícia de G2. Aumento original, 40x.

Antígenos do Mycoplasma pneumoniae mostraram-se em quantidade significativamente maior nos fragmentos com aneurismas, principalmente no tecido adiposo periadventicial $(p<0,001)$, mas também na camada adventícia $(p=0,02)$ e na camada íntima $(p=0,05)$. 
Tabela 9 - Média dos valores de \% de área ocupada por Mycoplasma pneumoniae na parede vascular em G1 e G2 e comparação entre os grupos

\begin{tabular}{|c|c|c|c|c|}
\hline MP & TAP & ADV & MED & INT \\
\hline G1 & $1,26 \pm 0,65$ & $2,13 \pm 1,49$ & $1,42 \pm 1,54$ & $3,26 \pm 2,18$ \\
\hline G2 & $5,75 \pm 4,62$ & $6,41 \pm 5,26$ & $1,42 \pm 1,26$ & $5,95 \pm 4,47$ \\
\hline$p$ & $p<0,001^{\ddagger}$ & $p=0,02^{\ddagger}$ & $\mathrm{p}=0,99^{\dagger}$ & $p=0,05^{\dagger}$ \\
\hline
\end{tabular}

MP - Mycoplasma pneumoniae

${ }^{\dagger}$ teste $t$

‡ Mann Whitney

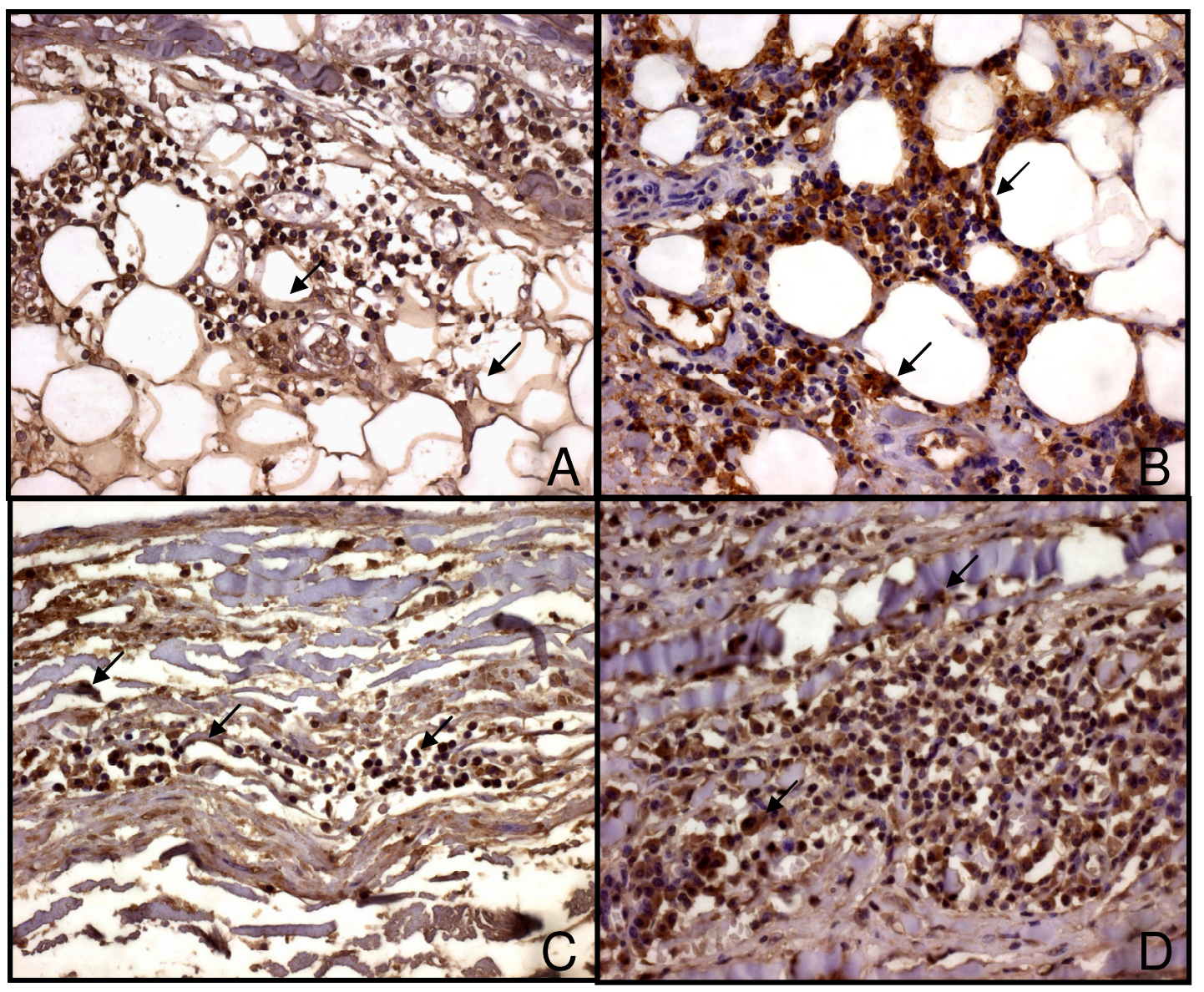

Figura 15 - Imuno-histoquímica apresentando células positivas para Mycoplasma pneumoniae. A tecido adiposo periadventicial de G1; B tecido adiposo periadventicial de G2; C adventícia de G1; D adventícia de G2. Aumento original, 40x. 


\subsection{CORRELAÇÕES ENTRE COLÁGENO, MMP-9, PPARS E AGENTES INFECCIOSOS}

Os testes de correlações foram realizados apenas com os valores obtidos no tecido adiposo periadventicial e na camada adventícia por serem as regiões da parede vascular que apresentaram diferenças significantes entre G1 e G2.

\subsubsection{Correlações significantes no Tecido Adiposo Periadventicial}

Houve correlação negativa entre diâmetro do aneurisma e quantidade de MMP-9 $(r=-0,70 ; p=0,02)$ no grupo 2. Além disso, a MMP-9 esteve correlacionada com a Chlamydophila pneumoniae nos fragmentos com aterosclerose $(r=0,74 ; p=0,01)$ e nos com aneurisma $(r=0,72 ; p=0,01)$. $O$ TIMP-1 apresentou correlação positiva com PPAR y nos fragmentos com aterosclerose $(r=0,94 ; p=0,02)$, mas correlação negativa nos fragmentos com aneurisma $(r=-0,82 ; p=0,01)$. Correlação negativa também foi observada entre o TIMP-1 e o Mycoplasma pneumoniae $(r=-0,89 ; p=0,03)$.

PPAR $\alpha$ e $y$ estiveram correlacionados somente no grupo da aterosclerose $(r=0,73 ; p=0,02)$, assim como os agentes infecciosos $(r=0,56$; $\mathrm{p}=0,05)$. Chlamydophila pneumoniae correlacionou-se com PPAR y nos dois grupos estudados ( $r=0,83 ; p=0,00$ em G1 e $r=0,56 ; p=0,05$ em G2), mas o Mycoplasma pneumoniae correlacionou-se com PPAR a apenas nos aneurismas $(r=0,61 ; p=0,04)$. 
As correlações significantes obtidas no tecido adiposo periadventicial (TAP) estão demonstradas na tabela 10.

TABELA 10 - Correlações entre MMP-9, TIMP-1, PPAR $\alpha$, PPAR $\gamma$, CP e MP presente no tecido adiposo periadventicial

\begin{tabular}{|c|c|c|c|c|}
\hline \multirow[t]{2}{*}{ Correlações em TAP } & \multicolumn{2}{|c|}{ G1 } & \multicolumn{2}{|c|}{ G2 } \\
\hline & $\mathbf{r}$ & $\mathbf{p}$ & $\mathbf{r}$ & $\mathbf{p}$ \\
\hline MMP-9 x diâmetro & - & - & $-0,70$ & $0,02^{\dagger}$ \\
\hline MMP-9 x CP & 0,74 & $0,01^{\ddagger}$ & 0,72 & $0,01^{\dagger}$ \\
\hline TIMP-1 x PPAR y & 0,94 & $0,02^{\ddagger}$ & $-0,82$ & $0,01^{\ddagger}$ \\
\hline TIMP-1 x MP & 0,33 & $0,36^{\ddagger}$ & $-0,89$ & $0,03^{\ddagger}$ \\
\hline PPAR $\alpha \times$ PPAR $y$ & 0,73 & $0,02^{\dagger}$ & 0,23 & $0,46^{\ddagger}$ \\
\hline $\mathrm{CP} \times \mathrm{MP}$ & 0,56 & $0,05^{\ddagger}$ & 0,21 & $0,50^{\dagger}$ \\
\hline CP $\times$ PPAR $y$ & 0,83 & $0,00^{\ddagger}$ & 0,56 & $0,05^{\ddagger}$ \\
\hline MP $\times$ PPAR $\alpha$ & 0,26 & $0,42^{\dagger}$ & 0,61 & $0,04^{\dagger}$ \\
\hline
\end{tabular}

$r=$ Coeficiente de correlação Spearman/Pearson

${ }^{\dagger}$ Pearson

‡ Spearman

\subsubsection{Correlações significantes na Adventícia}

A quantidade de colágeno presente na camada adventícia dos fragmentos com aterosclerose se correlacionou com quantidade de TIMP-1 $(r=0,85 ; p=0,00)$, PPARs $\alpha(r=0,61 ; p=0,03)$ e $Y(r=0,67 ; p=0,03)$, e de Chlamydophila pneumoniae $(r=0,64, p=0,02)$.

A MMP-9 ( $r=0,66 ; p=0,01$ em G1 e $r=0,58 ; p=0,03$ em G2) e TIMP-1 ( $r=0,74 ; p=0,01$ em $G 1$ e $r=0,56$ e $p=0,05$ em G2) na camada adventícia correlacionaram-se com PPAR a nos dois grupos estudados. Além disso, o 
TIMP-1 também se correlacionou com PPAR $Y(r=0,82 ; p=0,00)$ e Chlamydophila pneumoniae $(\mathrm{r}=0,72 ; \mathrm{p}=0,01)$ apenas no grupo com aterosclerose.

Assim como observado no tecido adiposo periadventicial, a Chlamydophila pneumoniae esteve correlacionada em ambos os grupos com PPAR y $(r=0,71 ; p=0,01$ em G1 e $r=0,60, p=0,02$ em G2), mas correlacionouse com Mycoplasma pneumoniae apenas no grupo com aneurisma $(r=0,54$; $p=0,05)$. Também no grupo com aneurisma o PPAR y correlacionou-se com o Mycoplasma pneumoniae $(r=0,58 ; p=0,03)$.

As correlações significantes obtidas na camada adventícia estão demonstradas na tabela 11. 
TABELA 11 - Correlações entre colágeno, MMP-9, TIMP-1, PPAR $\alpha$, PPAR $\gamma$, CP e MP presente na camada adventícia

\begin{tabular}{|c|c|c|c|c|}
\hline \multirow[t]{2}{*}{ Correlações na ADV } & \multicolumn{2}{|c|}{ G1 } & \multicolumn{2}{|c|}{ G2 } \\
\hline & $\mathbf{r}$ & $\mathbf{p}$ & $\mathbf{r}$ & $\mathbf{p}$ \\
\hline Colágeno x TIMP-1 & 0,85 & $0,00^{\ddagger}$ & $-0,14$ & $0,65^{\ddagger}$ \\
\hline Colágeno x PPAR $\alpha$ & 0,61 & $0,03^{\dagger}$ & 0,14 & $0,67^{\dagger}$ \\
\hline Colágeno x PPAR y & 0,67 & $0,03^{\ddagger}$ & 0,41 & $0,18^{\ddagger}$ \\
\hline Colágeno x CP & 0,64 & $0,02^{\ddagger}$ & $-0,10$ & $0,84^{\dagger}$ \\
\hline MMP-9 x PPAR $\alpha$ & 0,66 & $0,01^{\ddagger}$ & 0,58 & $0,03^{\dagger}$ \\
\hline TIMP-1 x PPAR $\alpha$ & 0,74 & $0,01^{\ddagger}$ & 0,56 & $0,05^{\ddagger}$ \\
\hline TIMP-1 x PPAR y & 0,82 & $0,00^{\ddagger}$ & 0,30 & $0,33^{\ddagger}$ \\
\hline CP x TIMP-1 & 0,72 & $0,01^{\ddagger}$ & 0,33 & $0,28^{\ddagger}$ \\
\hline $\mathrm{CP} \times \mathrm{PPAR} y$ & 0,71 & $0,01^{\ddagger}$ & 0,60 & $0,02^{\ddagger}$ \\
\hline $\mathrm{CP} \times \mathrm{MP}$ & 0,22 & $0,43^{\ddagger}$ & 0,54 & $0,05^{\dagger}$ \\
\hline MP $x$ PPAR y & $-0,09$ & $0,78^{\ddagger}$ & 0,58 & $0,03^{\ddagger}$ \\
\hline
\end{tabular}

$r=$ Coeficiente de correlação Spearman/Pearson

${ }^{\dagger}$ Pearson

‡ Spearman 
5. Discussão 
Aneurismas de aorta abdominal estão associados à idade avançada, sexo masculino, predisposição genética, hipertensão, tabagismo e aterosclerose. Entretanto, o relacionamento específico com os diversos fatores de risco e desenvolvimento dos aneurismas não está ainda completamente compreendido. Conhecimentos sobre os fatores biológicos e os mecanismos envolvidos na sua formação e desenvolvimento são necessários para aprimorar a abordagem desta doença (Wassef, 2007).

O presente estudo teve por finalidade comparar lesões ateroscleróticas com lesões aneurismáticas em fragmentos de aorta, correlacionando metaloproteinase 9, PPARs e agentes infecciosos como possíveis moduladores na formação de aneurismas.

\subsection{ALTERAÇÕES ESTRUTURAIS DA PAREDE VASCULAR}

A análise histológica dos fragmentos de aorta com aterosclerose (G1) e com aneurisma (G2) demonstrou diferenças entre os dois grupos em relação ao comportamento das camadas íntima e adventícia. Na camada íntima do grupo com aneurismas as placas apresentaram-se freqüentemente ulceradas e com presença variável de trombos, além da espessura da íntima estar diminuída quando comparada com a aterosclerose. Ulceração da placa parece ser um processo contínuo, onde a repetição do processo de ulceração e progressão da placa levaria ao afilamento da média e conseqüentemente a uma dilatação da parede vascular com formação de aneurismas (Zarins, 2001). O afilamento da camada média é uma alteração 
característica nos aneurismas (Aziz, 2007), mas não é exclusivo, sendo encontrado também no processo aterosclerótico (van der Wal, 1993). Comparando-se as duas lesões parece que a camada média dos aneurismas encontra-se mais afilada do que na aterosclerose (Pires, 2007), mas no presente estudo não foi observado diferenças entre a camada média dos dois grupos estudados.

A camada adventícia das aortas com aneurisma foi a porção do vaso que mais chamou a atenção dos observadores, apresentando diferenças histológicas significativas em relação às ateroscleróticas. Além da intensa inflamação presente nesta camada, o grupo com aneurisma apresentou um padrão diferente de colágeno. A quantificação do colágeno existente nas três porções da parede vascular revelou diferença estatística apenas na camada adventícia, onde a intensa fibrose presente nesta camada poderia estar associada ao espessamento da camada adventícia como uma resposta compensatória ao aumento do diâmetro vascular (Freestone, 1995). Segundo Mikami e Kyogoku (1994) em lesões aneurismáticas ocorre uma substituição da camada adventícia e da média por fibrose. Acredita-se que esta fibrose seja uma resposta do vaso ao estresse mecânico, onde a adventícia seria responsável por um remodelamento constritivo do segmento arterial (Michel, 2007), capaz de manter a estabilidade da aorta na ausência da elastina (Halloran, 1995). 


\subsection{METALOPROTEINASE $\quad-\quad 9$ E INIBIDOR TECIDUAL DA METALOPROTEINASE - 1}

Diversos estudos têm demonstrado que o processo de formação do aneurisma não é resultado de uma dilatação passiva, mas um processo complexo de remodelamento envolvendo síntese e degradação da matriz extracelular, onde os principais agentes envolvidos são as metaloproteinases (MMPs) (Ghorpade, 1996). MMPs são enzimas participantes em diversos processos fisiopatológicos, incluindo inflamação e remodelamento vascular, sendo capazes de degradar diversos componentes da matriz extracelular em situações patológicas ou não (Galis, 1994). Um dos principais aspectos histopatológicos dos aneurismas de aorta é o remodelamento destrutivo da parede vascular, principalmente da camada média. Estudos recentes têm focado no papel de várias MMPs como mediadores enzimáticos do aneurisma, com especial ênfase na MMP-2 e -9 (Eagleton, 2006), sendo esta última a mais estudada na patogenia dos aneurismas. Em tecidos aórticos normais esta protease não é encontrada em níveis significativos. Produzida principalmente por macrófagos, possui uma ampla capacidade de degradação de colágeno e elastina (Thompson, 1995).

A presença de MMP-9 foi observada em ambos os grupos estudados, entretanto, ao contrário do que foi descrito por McMillan et al (1997), de que os níveis de MMP-9 apresentam-se elevados em aneurismas de tamanho superior a $5,5 \mathrm{~cm}$, neste estudo foi observada uma correlação negativa entre 
a expressão da MMP-9 e o diâmetro do aneurisma, além da sua expressão ser semelhante nos fragmentos ateroscleróticos e aneurismáticos, havendo diferença estatística apenas no tecido adiposo periadventicial. Níveis elevados de MMP-9 na aterosclerose foram descritos na literatura por Galis e cols. (2002), que demonstraram a MMP-9 em fragmentos de carótidas atuando no remodelamento vascular e desestabilização da placa.

A MMP-9 é a principal responsável pela degradação da elastina, um dos componentes mais abundantes na camada média (Palombo, 1999). No presente estudo observou-se que não há diferenças na expressão de MMP9 e na espessura da média entre o grupo com aneurisma e o grupo com aterosclerose. Esse achado discorda dos dados de Patel et al (1996), que mostraram uma maior expressão da MMP-9 nas células musculares lisas obtidas de fragmentos com aneurisma quando comparados com as dos fragmentos com aterosclererose.

Nishimura e colaboradores (2003), sugeriram um importante papel da MMP-9 no desenvolvimento dos aneurismas e demonstraram que sua interação com o TIMP-1 é de fundamental importância na sua patogenia. No presente trabalho a expressão do TIMP-1 esteve aumentada nos fragmentos de aorta com aneurisma, apresentando diferença significativa no tecido adiposo periadventicial e na camada adventícia. Os resultados obtidos da expressão do TIMP-1 são semelhantes aos de Yamashita et al (2001) que comparando a expressão de MMP-9 e TIMP-1 em aortas com aneurisma e com aterosclerose oclusiva encontraram uma maior expressão das duas proteínas nas aortas aneurismáticas. 


\subsection{RECEPTORES ATIVADOS POR PROLIFERADORES DE PEROXISSOMOS}

Receptores ativados por proliferadores de peroxissomos (PPARs) são fatores de transcrição e têm sido descritos como reguladores de diversos processos metabólicos, incluindo inflamação, metabolismo de lípides e aterosclerose (Marx, 2004). Até a presente data foram identificadas três isoformas, das quais $\alpha$ e $\gamma$ parecem exercer efeitos anti-inflamatórios e vasculoprotetores (Tavares, 2007).

O presente trabalho mostrou presença de PPARs $\alpha$ e $\gamma$ em fragmentos de aorta humana com aterosclerose, com e sem aneurisma. De acordo com a revisão de Touyz e Schiffrin (2006) a imunomarcação para os PPARs foi observada nas células endoteliais, células musculares lisas, linfócitos e principalmente em macrófagos. PPAR $\alpha$, mas não $\gamma$, esteve aumentado nos fragmentos com aneurisma. Provavelmente isso se deve a uma diferença no padrão de expressão das duas isoformas nos macrófagos. Enquanto PPAR $\alpha$ está expresso em níveis elevados nos macrófagos (Castrillo, 2004), PPAR $\gamma$ parece se expressar em menor quantidade (Balakumar, 2007), assim como observado nas reações de dupla marcação.

PPARs são receptores nucleares, entretanto, diferentemente do que foi descrito por Revelo et al (2005), no presente trabalho foi observada uma intensa marcação citoplasmática. Entretanto, a presença citoplasmática dos PPARs foi descrita por outros autores. Padilla e colaboradores (2002) observaram imunopositividade para PPAR $\gamma$ no núcleo e no citoplasma de 
linfócitos B normais e alterados e Isaac et al (2006) demonstraram a presença das três isoformas de PPARs em astrocitomas e neuroblastomas. Nijsten et al (2005) encontraram marcação apenas citoplasmática em carcinoma de células escamosas. Apesar da expressão citoplasmática dos PPARs ter sido observada, sua real função no citoplasma ainda é desconhecida, e três hipóteses foram formuladas. Segundo Padilla e Isaac PPARs são sintetizados no citoplasma e ao se ligarem com seus agonistas são transportados para o núcleo, onde atuarão como reguladores da expressão gênica, em um processo similar ao que ocorre com NF-kB. Por outro lado, Theocharis e colaboradores (2002) acreditam que um possível defeito no processo de fosforilação acarreta em bloqueio desta proteína no citoplasma. Já Spinelli et al (2008) sugerem que os PPARs localizados no citoplasma tenham funções diferentes das de fator transcricional, sendo o assunto ainda não esclarecido.

A presença dos PPARs em aneurismas ainda é pouco descrita, mas tem sido sugerido que o PPAR $y$ tenha um importante papel na formação dos aneurismas (Soumian, 2005). Futuras investigações sobre o papel do PPAR nos aneurismas são necessárias. 


\subsection{AGENTES INFECCIOSOS}

A inflamação crônica da parede vascular é considerada fator determinante na injúria e progressão das lesões ateroscleróticas e aneurismáticas. Entretanto, o estímulo que inicia e sustenta este processo inflamatório não está completamente elucidado (Choi, 2002). Agentes infecciosos têm sido diretamente implicados como os principais estimuladores desta inflamação, sendo a Chlamydophila pneumoniae o agente mais estudado.

Estudos sobre fatores de risco para aneurismas demonstraram que sua formação está relacionada ao sexo e idade (Alexander, 2004). Grayston (2000) demonstrou que a prevalência da infecção por Chlamydophila pneumoniae aumenta com a idade, onde cerca de $80 \%$ dos homens acima de 65 anos possuem anticorpos contra clamídia. Corroborando com isso, diversos autores demonstraram a presença deste patógeno na parede vascular (Lindholt, 2006; Madjid, 2007). Assim como descrito por Karlsson et al (2000), a Chlamydophila pneumoniae esteve positiva nas áreas contendo invasão de células inflamatórias, principalmente em macrófagos e linfócitos. Entretanto, diferentemente destes autores que encontraram positividade em $80 \%$ dos casos, no presente trabalho, antígenos da Chlamydophila pneumoniae foram observados em todos os casos. Este achado está de acordo com estudos realizados em artérias coronárias ateroscleróticas, nos quais também foi encontrada positividade para antígenos da Chlamydophila 
pneumoniae em $100 \%$ dos segmentos coronarianos analisados (Higuchi, 2006; Sambiase, 2006).

Além da presença da Chlamydophila pneumoniae, foi observado, também, que todos os fragmentos tinham alguma área positiva para 0 Mycoplasma pneumoniae. Estes achados estão em acordo com achados prévios de Gois e colaboradores (2006) que mostraram uma co-infecção por estas duas bactérias em $100 \%$ de lesões ateroscleróticas iniciais de aorta, sugerindo possível participação destes agentes no desenvolvimento do processo aterogênico. A presença de DNA de Chlamydophila pneumoniae e Mycoplasma pneumoniae também foi demonstrada por Reszka et al (2008) em fragmentos de aorta macroscopicamente normais. Os autores no entanto não realizaram pesquisa quantitativa. Estudos prévios realizados em nosso laboratório também mostraram positividade para estes agentes em segmentos não ateroscleróticos, porém em níveis muito menores em relação aos segmentos comprometidos. Além disso, outros autores reforçam os achados sobre a presença de co-infeção em lesões ateroscleróticas: Momiyama et al (2004) e Goyal (2007) que mostraram níveis sorológicos de anticorpos contra ambos os agentes em pacientes com infarto agudo do miocárdio.

Apesar da Chlamydophila pneumoniae e do Mycoplasma pneumoniae apresentarem positividade nos dois grupos estudados, ambos patógenos estiveram em maior quantidade nos fragmentos com aneurisma. Higuchi e colaboradores (2003) descreveram uma relação simbiótica entre estes dois agentes, onde o micoplasma presente em grande quantidade na íntima 
poderia ser responsável pelo acúmulo de lípides no espaço subendotelial, ativando a resposta endotelial e provocando disfunção do sistema imune, facilitando assim a proliferação da clamidia e aumento da inflamação. Este aumento dos agentes infecciosos nos aneurismas poderia estar relacionado ao agravamento da lesão aterosclerótica, com evolução para o aneurisma.

\subsection{INTERAÇÕES ENTRE COLÁGENO, MMP-9, TIMP-1, PPARS E AGENTES INFECCIOSOS}

O aumento da fibrose na camada adventícia dos aneurismas tem sido observado por diversos pesquisadores (Rose, 1981; Leu, 1990; Rijbroek, 1994). No presente trabalho observou-se o aumento do colágeno da camada adventícia nos fragmentos com aneurisma, no entanto, este colágeno aumentado não apresentou correlações significativas com as demais variáveis estudadas. Por outro lado, nos fragmentos com aterosclerose este esteve correlacionado com o TIMP-1, PPARs e Chlamydophila pneumoniae.

Sabe-se que a homeostase normal da matriz extracelular é regulada pela interação entre as metaloproteinases e os seus inibidores naturais, os TIMPs (Elmore, 1998). Como o aumento na expressão dos TIMPs inibe a atividade das metaloproteinases, em conseqüência disso, ocorreria um aumento na produção de colágeno, justificando assim, a presença da correlação positiva entre as duas variáveis encontradas nos casos com aterosclerose. Entretanto, nos fragmentos com aneurisma, não houve correlação entre TIMPs e área de colágeno. 
Evidências recentes têm demonstrado que os PPARs possuem um papel importante na regulação do processo de fibrogênese (Wynn, 2008). Lakatos (2007), experimentalmente, demonstrou ação inibitória dos agonistas de PPARs na proliferação de fibroblastos na resposta fibrótica no pulmão. De acordo com esse achado, no presente estudo, foi observada uma correlação positiva entre o colágeno e os PPARs nos fragmentos com aterosclerose. Da mesma forma, neste mesmo grupo foi observada uma correlação positiva entre os PPARs $\alpha$ e y e o TIMP-1. Estes achados estão de acordo com os de Klimcakova (2007), onde os agonistas de PPAR parecem aumentar a expressão de TIMP-1. As correlações entre colágeno, TIMP-1 e PPARs nos fragmentos com aterosclerose, sugerem haver uma íntima associação entre estas variáveis.

Diferentemente, nos fragmentos com aneurisma, não foi observada correlação entre TIMP-1, colágeno e PPARs. Houve somente correlação entre PPAR a e TIMP-1, enquanto que o PPAR $y$ apresentou uma correlação negativa com TIMP-1 e com quantidade de colágeno. Além disso, nos fragmentos com aneurisma não foi observado correlação entre as duas isoformas de PPAR, correlação esta observada nos fragmentos com aterosclerose. Estes dados sugerem que o desenvolvimento dos aneurismas pode estar associado à perda da resposta interativa entre estas variáveis.

Os agentes infecciosos podem induzir ativação imunológica, provocando um dano na célula endotelial mediando, assim, um processo proteolítico na parede do aneurisma (Mussa, 2006). Clamídia e MMP-9 estiveram fortemente correlacionados em ambos os grupos estudados. De 
acordo com os achados de Vehmaan-Kreula e colaboradores (2001) a Chlamydophila pneumoniae é capaz de aumentar a capacidade de expressão de MMP-9 em macrófagos humanos. Provavelmente, esta interação seja um reflexo da capacidade da clamídia induzir a secreção de níveis elevados das citocinas pró-inflamatórias TNF- $\alpha$, IL-1 $1 \beta$, IL-6, MCP-1 e IL-12 (Netea, 2000), que estimulam a produção da MMP-9 (Shimizu, 2005). Diferentemente dos achados de Petersen et al (2002), que sugeriram não haver participação dessa bactéria em aneurisma de aorta, os dados observados neste trabalho indicam uma importante contribuição destes agentes na patogênese do aneurisma.

Huang e colaboradores (2005), estudando aterosclerose experimental, demonstraram que camundongos infectados com Chlamydophila pneumoniae têm uma maior expressão de PPAR $\gamma$. Esta correlação foi observada no presente trabalho, tanto no grupo com aterosclerose, como no grupo com aneurisma. Chlamydophila pneumoniae libera para o espaço extracelular antígenos como lipopolissacarídeos (LPS) e heat shock protein (HSP60) (Mahony, 2001). Aparentemente LPS pode aumentar a expressão de PPARs (Hunter, 2008), assim como a HSP (Latruffe, 1997)

Enquanto a Chlamydophila pneumoniae esteve correlacionada ao PPAR $\gamma$ nos dois grupos, o Mycoplasma pneumoniae correlacionou-se com PPAR $\alpha$ e com PPAR $\gamma$ apenas no grupo com aneurisma. PPAR $\alpha$ é ativado por uma grande variedade de ácidos graxos saturados e insaturados, incluindo o ácido palmítico, ácido linoleico e ácido aracdônico (Berger, 2002). 
Recentemente foram identificadas frações de lipoproteínas da membrana celular dos micoplasmas que são fortes ativadores de macrófagos, com atividade semelhante das LPS nas bactérias gram-negativas (Muhlradt, 2002). No Mycoplasma fermentans esta molécula foi denominada macrophage - activating lipopeptide - 2 (MALP-2), entretanto ainda não foi descrita a presença desta proteína no Mycoplasma pneumoniae. Por outro lado, estudos realizados por Shimizu et al (2005) analisando proteínas de membrana associadas a lipídeos (LAMPs) do Mycoplasma pneumoniae, identificou uma proteína de $21-\mathrm{kDa}$ que tem na sua constituição duas moléculas de ácido palmítico associados à cisteina na porção N-terminal que seria responsável pela indução da resposta imune ao Mycoplasma pneumoniae. A presença do ácido palmítico nas lipoproteínas de membrana do micoplasma poderia estar associado a ativação do PPAR a justificando, assim, a presença de correlação positiva entre eles.

A atividade anti-inflamatória dos PPARs parece estar refletida também na expressão das MMPs. Estudos recentes têm demonstrado que a MMP-9 pode ser inibida através da ação anti-inflamatória dos PPARs exercida sobre macrófagos (Zhang, 2007). Plutzky e colaboradores (1998) demonstraram que a expressão da MMP-9 está inibida apenas por PPAR $\gamma$. Por outro lado, os trabalhos de revisão de Duval et al (2002) e Libby et al (2007) descrevem a ação inibitória dos agonistas de PPAR $\alpha$ sobre a MMP-9. Os dados observados neste estudo mostraram que a MMP-9 se correlacionou positivamente com PPAR $\alpha$ em ambos os grupos. Esta correlação positiva do PPAR $\alpha$ poderia estar relacionada ao aumento do número de macrófagos 
na parede vascular dos fragmentos de aneurisma. Entretanto, outros estudos deverão ser realizados para confirmação e melhor entendimento destes dados.

\subsection{ADVENTÍCIA E O DESENVOLVIMENTO DE ANEURISMA DE AORTA: SEMELHANÇAS COM A PLACA INSTÁVEL.}

Os achados deste estudo estão diretamente relacionados à camada adventícia, pois as diferenças significantes entre os dois grupos foram identificadas nesta região. Estudos recentes têm demonstrado que a adventícia pode desempenhar um papel chave nos processos aterogênicos, alterando o foco dos pesquisadores, que durante muito tempo consideraram esta camada um elemento estrutural inerte da parede vascular (Yun, 2005). Muitos autores acreditam que a placa pode induzir alterações proteolíticas na média (Xu, 2001), entretanto, este conceito está sendo modificado após a caracterização da influência da inflamação crônica presente na adventícia (Sartore, 2001). A camada adventícia foi considerada o local com maior quantidade de inflamação da parede vascular (Moos, 2005), e sua intensidade foi associada à espessura diminuída da camada média e ao tamanho da placa na íntima (Houtkamp, 2001).

No desenvolvimento dos aneurismas de aorta ocorrem sérias alterações na adventícia. Assim como no presente estudo, tem sido observado que na camada adventícia ocorre um importante remodelamento, com aumento da espessura dessa camada à medida que a parede do vaso 
expande, migração de diversos tipos celulares como neutrófilos, macrófagos e linfócitos, além da expressão aumentada de metaloproteinases (McMillan, 1997; Daugherty, 2000; Silence, 2001).

Higuchi et al (2002) propuseram que a intensa inflamação presente na camada adventícia de artérias coronárias com placas ateroscleróticas instáveis seria responsável pelo aumento da luz do vaso e dilatação do segmento vascular (remodelamento positivo), processo semelhante ao que ocorre durante a formação dos aneurismas. Os mesmo autores sugerem que o infiltrado inflamatório seria responsável pela liberação de mediadores angiogênicos e conseqüentemente pelo aumento do número de vasos neoformados. No presente estudo aumento do vasa vasorum foi observado com maior freqüência nos fragmentos de aneurisma, não só na adventícia como na média, um local onde não há vascularização em aortas normais (Choke, 2006).

O aumento do vasa vasorum na aterosclerose poderia contribuir para o desenvolvimento da lesão com o suprimento de oxigênio e nutriente para o local da placa em expansão, perda da barreira endotelial e aumento da permeabilidade vascular e conseqüente extravasamento de fluído e proteínas (Langheinrich, 2007). Assim como descrito por Koch et al (1990), no presente estudo a inflamação na aterosclerose esteve menor quando comparada ao aneurisma, além de localizar-se preferencialmente na região perivascular do vasa vasorum. Segundo Langheinrich e colaboradores (2006) o vasa vasorum é responsável pela condução de células inflamatórias para a camada adventícia, justificando assim, esta localização perivascular. 
Por outro lado ele contribui para a cronificação da inflamação o que poderia desencadear a formação de aneurismas. O vasa vasorum e a camada adventícia parecem estar associados, também, à presença de agentes infecciosos, uma vez que proteínas de choque térmico (HSP) (Mussa, 2006) e antígenos da Chlamydophila pneumoniae e Mycoplasma pneumoniae, foram observadas em conjunto no interior de macrófagos presentes na camada adventícia (Higuchi, 2003). Segundo Karlsson et al (2000) após a fagocitose das bactérias no pulmão, macrófagos alveolares são capazes de atingir a circulação sistêmica e chegar à parede vascular em resposta a estímulos quimiotáticos. Portanto acredita-se que a porta de entrada dessas bactérias seria através do vasa vasorum, com aumento da severidade das lesões, nos fragmentos onde a concentração das bactérias na adventícia é maior (Vink, 2001).

Em adição ao vasa vasorum, a adventícia vascular contém componentes celulares como adipócitos e miofibroblastos. $\mathrm{O}$ tecido adiposo periadventicial está intimamente associado à camada adventícia, uma vez que não há uma clara delimitação entre os dois, sugerindo que ambos atuem em conjunto (Tellides, 2007). Moléculas secretadas pelos adipócitos como leptina, resistina e adiponectina, além de citocinas como MCP-1 (proteína quimioatraente de monócitos-1), TNF- $\alpha$ e IL-6 (Gollash, 2004) podem influenciar diretamente na homeostase da parede vascular, influenciando a função das células endoteliais, células musculares lisas e macrófagos (Fantuzzi, 2007). Estudos recentes realizados por Vela e colaboradores (2007) demonstraram que o tecido adiposo periadventicial com grande 
quantidade de macrófagos infiltrados está associado à severidade das lesões ateroscleróticas. Se os aneurismas estão sendo considerados uma evolução da doença aterosclerótica, isso justificaria a intensa inflamação presente no tecido adiposo periadventicial destes fragmentos, além do aumento da expressão de MMP-9, PPAR $\alpha$ e da presença de agentes infecciosos observados no presente estudo.

Diversos estudos têm demonstrado uma forte associação entre aneurisma de aorta e aterosclerose. Entretanto diferenças histológicas e epidemiológicas entre estas doenças têm colocado em dúvida esta clássica associação (Wanhainem, 2005). Neste trabalho as correlações entre as diversas variáveis mostraram diferenças significantes entre as duas doenças.

Lesões ateroscleróticas são freqüentemente encontradas na parede vascular dos fragmentos de aneurismas de aorta, entretanto, a maioria destas lesões não evolui para aneurismas (Wassef, 2007). Além disso, a principal dúvida entre os pesquisadores é porque aortas com lesões ateroscleróticas em alguns indivíduos evoluem para doença oclusiva e em outros para dilatação aneurismática (Xu, 2001). Por outro lado, questões semelhantes a esta também são observadas em artérias menores como coronárias e carótidas.

As lesões ateroscleróticas podem evoluir de duas formas morfologicamente distintas, e que muitas vezes são observadas no mesmo paciente. Análises histológicas de artérias coronárias mostram que as lesões consideradas estáveis possuem grande quantidade de fibrose e pouca 
gordura. Ocasionam uma diminuição e obstrução da luz vascular, estando geralmente associadas à angina (Libby, 2001). Já as placas instáveis apresentam intensa inflamação, um grande centro necrótico, circundado por uma fina camada de fibrose, geralmente com presença de trombos. Porém ao contrário das lesões estáveis, neste tipo de lesão a luz do vaso geralmente é preservada. Esta diferença entre os dois tipos de lesões parece estar associada ao processo de remodelamento da matriz extracelular (Uemura, 2006).

Pasterkamp et al (1997) demonstraram haver um remodelamento vascular compensatório em reposta ao depósito de gordura na íntima do vaso, com interferência no tamanho da luz. Posteriormente, Bezerra e colaboradores (2001) demonstraram que o infarto agudo do miocárdio fatal é causado por lesões onde há remodelamento vascular positivo. As lesões consideradas com remodelamento negativo têm diminuição da luz vascular e estão relacionadas às placas estáveis, enquanto as que têm a luz do vaso relativamente preservada pela distensão da parede vascular, são consideradas com remodelamento positivo e estão usualmente associadas a grande placas instáveis. No mesmo trabalho, Bezerra e colaboradores observaram que lesões com remodelamento positivo freqüentemente apresentavam grande quantidade de gordura e maior susceptibilidade à ruptura e trombose. Essa susceptibilidade foi sugerida estar associada ao grande número de macrófagos presentes na parede vascular destas coronárias e a liberação de metaloproteinases. 
De forma similar ao que foi descrito nas artérias coronárias, este processo de remodelamento também ocorre na aorta. Benvenuti e colaboradores (2005) estudando o processo aterosclerótico em segmentos de aorta demonstraram que a porção torácica da aorta está associada ao remodelamento positivo da aorta, enquanto que a porção abdominal pode apresentar tanto o remodelamento positivo quanto o negativo.

Paralelamente, Zarins et al (2001), analisando a influência da aterosclerose na formação de aneurismas, demonstrou que a aterosclerose está associada ao aumento do tamanho da aorta, principalmente na porção abdominal, com profunda alteração da estrutura da camada média, sugerindo que estas alterações são fatores que predispõem à formação de aneurismas. Estes dados em conjunto sugerem que aneurismas de aorta apresentam um padrão de remodelamento vascular positivo, semelhante ao observado nas lesões ateroscleróticas instáveis das artérias coronárias.

Recentemente têm-se sugerido a participação de fatores genéticos como os principais desencadeadores do processo de formação dos aneurismas. Os principais genes envolvidos são os responsáveis pela transcrição de colágeno e elastinas, enzimas de atividade proteolítica e seus inibidores, além dos genes codificadores de citocinas (Sandford, 2007).

Os achados deste estudo mostram que os fragmentos de aneurisma de aorta, apesar de possuírem algumas diferenças histológicas com os fragmentos ateroscleróticos, também possuem diversas semelhanças. Nos dois grupos estudados, MMP-9, TIMP-1 e PPARs estão expressos, e os agentes infecciosos estão presentes, sendo no entanto em maior quantidade 
nos fragmentos com aneurisma. Além disso, a falta de uma resposta integrada do TIMP e PPARs, frente aos agentes infecciosos pode explicar em parte o desenvolvimento de fragmentação do colágeno e desenvolvimento de dilatação do vaso. Dessa forma, a associação das lesões ateroscleróticas a fatores genéticos e ambientais como a co-infecção com maior proliferação de agentes infecciosos poderia explicar a formação de aneurismas. 
6. Conclusão 
A análise dos fragmentos ateroscleróticos de aorta com e sem aneurisma demonstrou:

a) $\quad$ MMP-9 e TIMP-1 estão mais expresso nos aneurismas, o primeiro apenas na gordura periadventicial e o segundo nessa mesma área e na adventícia

b) As duas isoformas dos PPARs estão presentes nos aneurismas, sendo o PPAR a mais expresso na gordura periadventicial e adventícia dos fragmentos com aneurisma, enquanto PPAR y está expresso de forma semelhante no dois tipos de lesão;

c) Antígenos de Chlamydophila pneumoniae e Mycoplasma pneumoniae estão presentes nos dois tipos de lesão, porém em maior quantidade na gordura periadventicial e adventícia dos aneurismas.

d) Na aterosclerose há correlação entre PPARs e TIMP-1, mas esta resposta não foi observada nos aneurismas.

Em conclusão, os dados obtidos demonstram haver semelhanças entre aneurismas de aorta e lesões ateroscleróticas não aneurismáticas principalmente em relação à presença de co-infecção por Chlamydophila pneumoniae e Mycoplasma pneumoniae. Quantidade aumentada dos mesmos na adventícia e tecido adiposo periadventicial nos aneurismas e a falta de correlação entre a expressão de PPARs e TIMP sugerem que uma inadequada resposta 
imune do hospedeiro à presença desses agentes pode estar ligada ao desenvolvimento dos aneurismas. 


\section{Anexos}


$+$

Mem. CC. 1863

São Paulo, 17 de novernbro de 2005.

$\grave{A}$

Profa. Dra. Maria de Lourdes Higuchi

Ref.: Protocolo de Pessquisa SDC 2589/05/009

A Comissão Científica do Instituto do Coração, apreciou na sessão 484/05/20 de 17.11.2005 a solicitação de dispensa do termo de responsabilidade assinado pelo paciente do Protocolo de Pesquisa SDC 2589/05/009 "Diferentes Enfoques na Patogênese das Placas Vulneráveis, Remodelamento Vascular e Aneurismas: Influência do Trombo Mecánismos Inflamatórios de Agente Infecciosos", e foi o seguinte parecer: "Aprovado".

Atenciosamente,

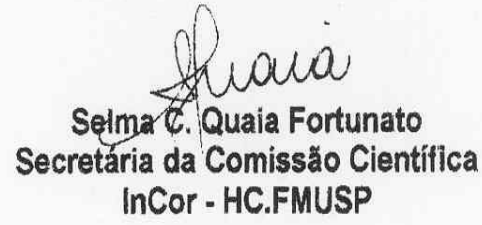


Quadro 1 - Dados clínicos dos pacientes incluídos em G1

\begin{tabular}{|c|c|c|c|c|c|c|}
\hline № & Idade & Sexo & HAS & DLP & $\mathrm{DAC}$ & DM \\
\hline 1 & 69 & $F$ & + & - & + & + \\
\hline 2 & 71 & $\mathrm{M}$ & + & - & + & - \\
\hline 3 & 67 & $\mathrm{~F}$ & + & - & + & - \\
\hline 4 & 78 & $M$ & + & - & + & + \\
\hline 5 & 76 & $\mathrm{M}$ & + & - & + & - \\
\hline 6 & 61 & $M$ & + & - & + & + \\
\hline 7 & 72 & $M$ & + & + & + & - \\
\hline 8 & 65 & $\mathrm{M}$ & + & - & + & + \\
\hline 9 & 50 & $M$ & + & - & + & - \\
\hline 10 & 81 & $\mathrm{~F}$ & + & - & + & - \\
\hline 11 & 76 & $\mathrm{M}$ & + & - & + & + \\
\hline 12 & 69 & $\mathrm{M}$ & + & - & + & - \\
\hline 13 & 75 & $\mathrm{~F}$ & + & + & + & + \\
\hline 14 & 74 & $M$ & - & - & + & - \\
\hline
\end{tabular}

HAS - hipertensão arterial; DLP - dislipidemia; DAC - doença arterial coronariana; DM - diabetes mellitus 
Quadro 2 - Dados clínicos dos pacientes submetidos à cirurgia de correção de aneurisma (G2)

\begin{tabular}{|c|c|c|c|c|c|c|c|c|c|c|}
\hline № & Idade & Sexo & Localização & Aneurisma $(\mathrm{cm})$ & Tabagismo & HAS & DLP & DAC & Obesidade & $\mathrm{DM}$ \\
\hline 1 & 65 & $M$ & Abdominal & 5,0 & + & - & - & - & - & - \\
\hline 2 & 64 & $\mathrm{~F}$ & Abdominal & 7,0 & - & + & - & - & - & - \\
\hline 3 & 54 & $\mathrm{~F}$ & Ascendente & 6,4 & + & + & - & - & - & - \\
\hline 4 & 78 & $M$ & Abdominal & & & & & & & \\
\hline 5 & 76 & $\mathrm{~F}$ & Abdominal & & & & & & & \\
\hline 6 & 75 & $M$ & Ascendente & 7,0 & - & + & + & + & - & + \\
\hline 7 & 75 & M & Abdominal & 5,0 & + & + & + & + & - & + \\
\hline 8 & 69 & $M$ & llíaca & 8,0 & + & + & + & - & + & - \\
\hline 9 & 69 & $M$ & Torácica & 6,5 & + & + & - & - & - & + \\
\hline 10 & 64 & $M$ & Abdominal & 8,6 & - & + & - & - & - & - \\
\hline 11 & 67 & $\mathrm{~F}$ & Torácica & 6,0 & - & + & + & - & + & - \\
\hline 12 & 65 & $M$ & Infra renal & 7,0 & + & + & + & - & - & + \\
\hline 13 & 70 & $M$ & Abdominal & 5,0 & + & + & + & - & + & - \\
\hline 14 & 49 & $M$ & Abdominal & 6,2 & + & + & + & - & - & + \\
\hline
\end{tabular}

HAS - hipertensão arterial; DLP - dislipidemia; DAC - doença arterial coronariana; DM - diabetes mellitus 
8. Referências Bibliográficas 
Achneck H, Modi B, Shaw C, Rizzo J, Albornoz G, Fusco D, Elefteriades J. Ascending thoracic aneurysms are associated with decreased systemic atherosclerosis. CHEST. 2005; 128:1580-6.

Allaire E, Forough R, Clowers M, Starche B, Clowers AW. Local overexpression of TIMP-1 prevents aortic aneurysms degeneration and rupture in a rat model. J Clin Invest. 1998; 102:1413-20.

Alexander JJ. The pathobiology of aortic aneurysms. J Surg Res. 2004; 17:163-75.

Andrian E, Mostefaoui Y, Rouabhia M, Grenier, D. Regulation of matrix metalloproteinases and tissue inhibitors of matrix metalloproteinases by Porphyromonas gingivalis in an engineered human oral mucosa model. $\mathbf{J}$ Cell Physiol. 2007; 211:56-62.

Avron, A, Gallily R. Mycoplasma stimulates the production of oxidative radicals by murine peritoneal macrophages. Leukoc Biol. 1995; 57:264-8.

Aziz $\mathrm{F}$, Kuivaniemi $\mathrm{H}$. Role of matrix metalloproteinase inhibitors in preventing abdominal aortic aneurysm. Ann Vasc Surg. 2007; 21:392-401. 
Balakumar P, Rose M, Gant SS, Krishan P, Singh M. PPAR dual agonist: are they opening Pandora's box? Pharmacol Res. 2007; 56:91-8.

Benvenuti LA, Onishi RY, Gutierrez PS, Higuchi ML. Different patterns of atherosclerotic remodeling in the thoracic and abdominal aorta. CLINICS. $2005 ; 60: 355-60$.

Berger J, Moller ED. The mechanisms of activation of PPARs. Ann Rev Med., 2002; 53:409-35.

Bernucci P, D’amati G, de Santis F, Di Marzo L, Sapienza P, Cavallaro A, Fiorani P, Gallo P. Inflammatory aneurysms of the abdominal aorta: anatomo-clinical study on 16 cases and pathogenic hypothesis. G Ital Cardiol. 1992; 22:1381-8.

Bettmann MA, Dake MD, Hopkins N, Katzen BT, White CJ, Eisenhauer AC, Pearce WP, Rosenfield KA, Smalling RW, Sos TA, Venbrux AC. Atherosclerotic vascular disease conference, writing group VI: revascularization. Circulation. 2004; 109:2643-50.

Bezerra HG, Higuchl ML, Gutierrez PS, Palomino SAP, Silvestre JM, Libby P, Ramirez JAF. Atheromas that cause fatal thrombosis are usually large and frequently accompanied by vessel enlargement. Cardiovasc Pathol. 2001; 10:189-98. 
Broaders SA, Hooper WC, Phillips DJ, Talkington DF. Mycoplasma pneumoniae subtype-independent induction of proinflammatory cytokines in THP-1. Microbiol Pathol. 2006; 40:286-92.

Castrillo A, Tontonoz P. Nuclear receptors in macrophage biology: At the crossroads of lipids metabolism and inflammation. Annu Rev Cell Dev Biol. $2004 ; 20:, 455-80$.

Chan PJ, Seraj IM, Kalugdan TH, King A. Prevalence of Mycoplasma conserved DNA in malignant ovarian cancer detected using sensitive PCRELISA. Gynecol Oncol. 1996; 63:258-60.

Chan WL, Pejnovic N, Hamilton H, Liew TV, Popadic D, Poggi A, Khan SM. Atherosclerotic abdominal aortic aneurism and the interaction between autologous human plaque-derived vascular smooth muscle cells, type 1 NKT and helper cell. Cir Res. 2005; 96:675-83.

Chinetti G, Lestavel S, Bocher V, Remaley AT, Neve B, Torra IP, Teissier E, Minnich A, Jaye M, Duverger N, Brewer HB, Fruchart JC, Clavey V, Staels B. PPAR-alpha and PPAR-gamma activators induce cholesterol removal from human macrophage foam cells through stimulation of the ABCA1 pathway. Nat Med. 2001; 7:53-8. 
Choi EY, Dongsoo K, Hong BK, Kwon HM, Song YG, Byun KH, Park HY, Whang KC, Kim HS. Up-regulation of extracellular matrix metalloproteinase inducer (EMMPRIN) and gelatinase in human atherosclerosis infected with Chlamydia pneumoniae infection in the progression of atherosclerosis. Exp Mol Med. 2002; 34:391-400.

Choke E, Cockerill G, Wilson WRW, Sayed S, Dawson J, Loftus I, Thompson MM. A review of biological factors implicated in abdominal aortic aneurysms rupture. Eur J Endovasc Surg. 2005; 30:227-44.

Choke E, Thompson MM, Dawson J, Wilson WRW, Sayed S, Loftus I, Cockerill GW. Abdominal aortic aneurysms rupture is associated with increased medial neovascularization and overexpression of proangiogenic cytokines. Artherioscler Thromb Vasc Biol. 2006; 26:2077-82.

Daugherty A, Manning MW, Cassis LA. Angiotensin II promotes atherosclerotic lesions and aneurysms in apolipoprotein E-deficient mice. $\mathbf{J}$ Clin Invest. 2000; 105:1605-12.

Dollery CM, McEwan JR, Henney AM. Matrix metalloproteinases and cardiovascular disease. Circ Res. 1995; 77:863-8.

Duval C, Chinetti G, Trottein F, Fruchart JC, Staels B. The role of PPARs in atherosclerosis. Trends Mol Med. 2002; 8:422-30. 
Eagleton MJ, Ballard N, Lynch E, Srivastava SD, Upchurch GR, Stanley JC. Early increased MT1-MMP expression and late MMP-2 and MMP-9 activity during angiotensin II induced aneurysms formation. J Surg Res. 2006; $135: 345-51$

Elmore JR, Keister BF,Franklin DP, Youkey JR, Carey DJ. Expression of matrix metalloproteinases and TIMPs in human abdominal aortic aneurysms. Ann Vasc Surg. 1998; 12:221-8.

Espinola-Klein C, Rupprecht HJ, Blankenberg S, Bickel C, Kopp H, Victor A, Hafner G, Prellwitz W, Schlumberger W, Meyer J. Impact of infectious burden on progression of carotid atherosclerosis. Stroke. 2002; 33:2581-6.

Fantuzzi G, Mazzone T. Adipose tissue and atherosclerosis: exploring the connection. Arter Throm Vasc Biol. 2007, 27:996-1003.

Filho GB. Bogliolo - Patologia. 6 ed. Guanabara - Koogan, p.393-415, 2000.

Fong IW. Emerging relation between infectious disease and coronary artery disease and atherosclerosis. CMAJ. 2000; 163:49-56. 
Forrester ND,Cruickshank SM, Scott DJ, Carding SR. Functional characterization of $\mathrm{T}$ cells in abdominal aortic aneurysms. Immunology. 2005; 115:262-70.

Freestone T, Turner RJ, Coady A, Higman DJ, Greenhalgh RM, Powell JT. Inflammation and matrix metalloproteinases in the enlarging abdominal aortic aneurysms. Arterioscler Thromb Vasc Biol. 1995; 15:1145-51.

Freestone T, Turner RJ, Higman DJ, Lever MJ, Powell JT. Influence of hypercholesterolemia and adventitial inflammation on the development of aortic aneurysms in rabbits. Arterioscler Thromb Vasc Biol. 1997; 17:10-7.

Galis ZS, Sukhova GK, Lark MW, Libby P. Increased expression of matrix metalloproteinases and matrix degrading activity in vulnerable regions of human atherosclerotic plaques. J Clin Invest. 1994; 94:2493-503.

Galis ZS, Johnson C, Godin D, Magid R, Shipley JM, Senior RM, Ivan E. Target disruption of the matrix metalloproteinase-9 impairs smooth muscle cell migration and geometrical arterial remodeling. Circ Res. 2002; 91:852-9. 
Galle C, Schandene L, Stordeur P, Peignois Y, Ferreira J, Wautrecht JC, Dereume JP, Goldman M. Predominance of type 1 CD4+ T cells in human abdominal aortic aneurysm. Clin Exp Immunol. 2005; 142:519-27.

Goyal P, Kale SC, Chaudhry R, Chauhan S, Shah N. Association of common chronic infections with coronary artery disease in patients without any conventional risk factor. Indian J Med Res. 2007; 125:129-136.

Gois J.M, Higuchi ML, Reis MM, Diament J, Sousa JM, Ramires JAF, Oliveira SA. Infectious agents, inflammation, and growth factors: how do they interact in the progression or stabilization of mild human atherosclerotic lesions. Ann Vasc Surg. 2006; 20:638-45.

Gollasch M, Dubrovska G. Paracrine role for periadventitial adipose tissue in the regulation of arterial tone. Trends Pahamacol Sci. 2004; 25:647-53.

Ghorpade A, Baxter BT. Biochemistry and molecular regulation of matrix macromolecules in abdominal aortic aneurysms. Ann N Y Acad Sci. 1996; 800:138-50.

Guo DC, Papke CL, He R, Milewicz DM. Pathogenesis of thoracic and abdominal aortic aneurysms. Ann N Y Acad Sci. 2006; 1085:.339-52. 
Grayston JT. Background and current knowledge of Chlamydia pneumoniae and atherosclerosis. J Infect Dis. 2000; 181:S402-10.

Halloran BG, Baxter BT. Pathogenesis of aneurysms. Semin Vasc Surg. $1995 ; 8: 85-92$.

Halme S, Juvonen T, laurila A, Juvonen J, Mosorin M, Saikku P, Surcel HM. Chlamydia pneumoniae reactive $\mathrm{T}$ lymphocytes in the wall of abdominal aortic aneurysms. Eur J Clin Invest. 1999; 29:546-52.

Hardgger D, Nadal D, Bossart W, Atwegg M, Dutly F. Rapid detection of Mycoplasma pneumoniae in clinical samples by real time - PCR. J Microbiol Methods. 2000; 41:45-51.

Hayashi H, Hidaka F, Kumazi T, OCHI M. Serial assessment of the development of inflammatory abdominal aortic aneurysm from ordinary atherosclerotic abdominal aortic aneurysm using multidetector-row computed tomographic angiography. Heart Vessel. 2006; 21:334-7.

Hellmann DB, Grand DJ, Freischlag JA. Inflammatory abdominal aortic aneurysms. JAMA. 2007; 297:395-400.

HiguchI ML, Sambiase NV, Palomino SAP, Gutierrez PS, Aiello VD, Ramires JAF. Detection of Mycoplasma pneumoniae and Chlamydia pneumoniae in 
ruptured plaques atherosclerotic plaques. Braz J Med Biol Res. 2000; 33:1023-6.

Higuchi ML, Ramires JAF. Infectious agents in coronary atheromas: a possible role in the pathogenesis of plaque rupture and acute myocardial infartion. Rev Inst Med Trop. 2002; 44:217-24.

Higuchi ML, Gutierrez PS, Bezerra HG, Palomino SAP, Aiello VD, Silvestre JML, Libby P, Ramires JAF. Comparison between adventitial and intimal inflammation of ruptured and nonruptured atherosclerotic plaques in human coronary arteries. Arq Bras Cardiol. 2002; 79:20-4.

Higuchi ML, Reis MM, Sambiase NV, Palomino SAP, Castelli JB, Gutierrez PS, Aiello VD, Ramires JAF. Co-infection with Mycoplasma pneumoniae and Chlamydia pneumoniae in ruptured plaques associated with acute myocardial infarction. Arq Bras Cardiol. 2003: 81:12-22.

Higuchi ML, Gois JM, Higuchi dos Santos MH, Diament J, Sousa JM, Ramires JAF, Oliveira SA. Co-infection ratios versus inflammation, growth factors and progression of early atheromas. APMIS. 2006; 114:338-44.

Hobeika MJ, Thompson RW, Muhs BE, Brooks PC, Gagne PJ. Matrix metalloproteinases in peripheral vascular disease. J Vasc Surg. 2007; 45:849-57. 
Hornebeck W, Lambert E, Petitfrère E, Bernard P. Benefical and detrimental influences of tissue inhibitor of metalloproteinase-1 (TIMP-1) in tumor progression. Biochimie. 2005; 87:377-83.

Houtkamp MA, Boer OJ, van der Loos CM, van der WAL AC, Becker AE. Adventitial infiltrates associated with advanced atherosclerosis plaques: Structural organization suggests generation of local humoral immune responses. J Pathol. 2001; 193:263-9.

Hovsepian DM, Ziporin SJ, Sakural MK, Lee JK, Curcl JA, Thompson RW Elevated plasma levels of matrix metalloproteinase-9 in patients with abdominal aortic aneurysms: a circulating marker of degenerative aneurysm disease. J Vasc Interv Radiol. 2000; 11:1345-52.

Huang B, Dong Y, Mai W, Li Y. Effect of Chlamydia pneumoniae infection and hyperlipidaemia on the expression of PPAR $\gamma$, P50 and c-Fos in aortic endothelial cells in C57bL/6J mice. Acta Cardiol. 2005; 60:43-9.

Hunter RL, Choi DY, Ross SA, Bing G. Prospective properties afforded by pioglitazone against intrastriatal LPS in Sprague-Dawley rats. Neurosci Lett. 2008; 432:198-201.

Isaac AO, Kawikova I, Bothwell ALM, Daniels CK, Lai LCK. Manganese treatment modulates the expression of peroxisome proliferator-activated 
receptors in astrocytoma and neuroblastoma cells. Neuroschem Res. 2006; 31:1305-16.

Juvonen J, Juvonen T, Laurila A, Alakarppa H, Lounatmaa K, Surcel HM. Demonstration of Chlamydia pneumoniae in the walls of abdominal aortic aneurysms. J Vasc Surg. 1997; 25:499-505.

Karlsson L, Gnarpe J, Naas J, Olsson G, Lindholm J, Steen B, Gnarpe H. Detection of viable Chlamydia pneumoniae in abdominal aortic aneurysms. Eur J Vasc Surg. 2000; 19:630-5.

Keeling WB, Armstrong DO, Stone PA, Bandyk DF, Shames ML, Tampa FL. An overview of matrix metalloproteinases in the pathogenesis and treatment of abdominal aortic aneurysms. Vasc Endovasc Surg. 2005; 39:457-64.

Kersten S, Desvergne B, Wahli W. Roles of PPARs in health and disease. Nature. 2000; 405:421-4.

Kiec-Wilk B, Dembinska-Kiec A, Olszanecka A, Bodzioch M, KaweckaJaszcz K. The selected pathophysiological aspects of PPARs activation. $\mathbf{J}$ Physio Pharmacol. 2005; 56:149-62. 
Kim MP, Gaydos CA, Wood BJ, Hardick JP, Zhang Y, Wahl, L.M. Chlamydia pneumoniae enhances cytokines-stimulated human monocytes matrix metalloproteinases through a prostaglandine E2-dependent mechanism. Infect Immun. 2005; 73:632-4.

Klein DG. Thoracic aortic aneurysms. J Cardiovasc Nurs. 2005; 20:245-50.

Kliewe AS, Umesono K, Noonan DJ, Heyman RS, Evans RM. Convergence of 9-cis retinoic acid and peroxisome proliferator signaling pathway through heterodimer formation of their receptors. Nature. 1992, 358:771-4.

Klimcakova E, Moro C, Mazzucotelli A, Viguerie N, Galitzky J, Stich V, Langin D. Profiling of adipokines secreted from human subcutaneous adipose tissue in response to PPAR agonists. Biochem Biophys Res Commun. 2007; 358:897-902.

Koch AE, Haines GK, Rizzo RJ, Radosevich JA, Pope RM, Robinson PG, Pearce WH. Human abdominal aortic aneurysms - Immunophenotypic analysis suggesting an immune - mediated response. Am J Pathol. 1990; 137:1199-213. 
Kota BP, Huang THW, Roufogalis BD. An overview on biological mechanisms of PPARs. Pharmacol Res. 2005; 51:85-94.

Kol A, Libby P. The mechanisms by which infectious agents may contribute to atherosclerosis and its clinical manifestations. TMV. 1998; 8:191-9.

Lakatos HF, Thatcher TH, Kottmann RM, Garcia TM, Phipps RP, Sime PJ. The role of PPAR in lung fibrosis. PPAR Res.2007; 2007:71323.

Langheinrich AC, Michniewcz A, Sedding DG, Walker G, Beighley PE, Rau WS, Bohle RM, Ritman EL. Correlation of vasa vasorum neovascularization and plaque progression in aortas of apolipoprotein $\mathrm{E}^{-/-} /$low-density lipoprotein $^{-/}$double knockout mice. Arterioscler Thromb Vasc Biol. 2006; $26: 347-52$.

Langheinrich AC, Kampschulte M, Buch T, Bohle RM. Vasa vasorum and atherosclerosis - Quid novi? Thromb Haemost. 2007; 97:873-9.

Latruffe N, Vamecq J. Peroxisome proliferators and peroxisome proliferator activated receptors (PPARs) as regulators of lipid metabolism. Biochimie. $1997 ; 79: 81-94$. 
Leclercq A, Houard X, Philippe M, Ollivier V, Sebbag U, Meilhac O, Michel JB. Involvement of intraplaque hemorrhage in aterothrombosis evolution via neutrophil protease enrichment. J Leukoc Biol. 2007.; 82:1420-9,.

Leu HJ. Inflammatory abdominal aortic aneurysms: a disease entity? Histological analysis of 60 cases of inflammatory aortic aneurysms of unknown aetiology. Virchows Arch Patho Anat Histopathol. 1990; 417:427-33.

Libby P, Sukhova G, Lee RT, Galis ZS. Cytokines regulate vascular functions related to stability of the atherosclerotic plaque. J Cardiovasc Pharmacol. 1995; 25:S9-12.

Libby P. Heart disease: a textbook of cardiovascular medicine. In Brauwald E, Zipes DP, Libby P. Ed WB Saunders Company, $20016^{\text {Th }}$ edition; p.995-1001

Libby P, Ridker PM. Inflammation and atherosclerosis: Role of C-reactive protein in risk assessment. Am J Med. 2004; 116: S 9-16.

Libby P, Plutzky J. Inflammation in diabetes mellitus: Role of peroxisome proliferator - activated receptor - $\alpha$ and peroxisome proliferator - activated receptor - $\gamma$ agonists. Am J Cardiol. 2007; 99:B27-40. 
Lijnen HR. Metalloproteinases in development and progression of vascular disease. Pathophysiol Haemost Thormb. 2004; 33:275-81.

Lindholt JS, Ashton HA, Scott RAP. Indicators of infection with Chlamydia pneumoniae are associated with expression of abdominal aortic -aneurysms. J Vasc Surg. 2001; 34:212-5.

Lindholt JS, Shi GP. Chronic inflammation, immune response and infection in abdominal aortic aneurysms. Eur J Endovasc Surg. 2006; 31:453-63.

Luster AD. Chemokines-chemotactic cytokines that mediate inflammation. $\mathbf{N}$ Engl J Med. 1998; 338:436-45.

Madjid M, Vela D, Khalili-Tabrizi H, Casscells SW, Litovsky S. Systemic infections cause exaggerated local inflammation in atherosclerotic coronary arteries: clues to the triggering effects of acute infections on acute coronary syndromes. Tex Heart Inst J. 2007; 34:11-8.

Mahara B, Berg H, Scheffer GJ, van der Zee A, Bergmans A, Miseré J, Kluytmans J, Peeters M. Correlation between detection methods of Chlamydia pneumoniae in atherosclerotic and non-atherosclerotic tissues. Diagn Microbiol Infect Dis. 2001; 39:139-43. 
Mahony JB, Coombes BK. Chlamydia pneumoniae and atherosclerosis: does the evidence support a causal or contributory role?. FEMS Microbiol Lett. $2001 ; 197: 1-9$.

Marx N, Sukhova G, Murphy C, Libby P, Plutzky J. Macrophages in human atheroma contain PPAR gamma: Differentiation-dependent peroxisome proliferator-activated receptor gamma (PPAR gamma) expression and reduction of MMP-9 activity through PPAR gamma activation in mononuclear phagocytes in vitro. Am J Pathol. 1998; 153:17-23.

Marx N, Duez H, Fruchart JC, Staels B. Peroxisome proliferator activated receptors and atherogenesis: Regulators of gene expression in vascular cells. Circ Res. 2004; 94:1168-78.

Mazur E, Niedzwiadek J, Wolski A, Siezieniewska-Skowronska Z, Zywick W, Korolczuk A, Korobowicz E, Koziol-Montewka M. Chlamydia pneumoniae infection in abdominal aortic aneurysms (AAA) patients and its clinical impact. Pol J Pathol. 2004; 55:155-64.

McMillan WD, Tamarina NA, Cipollone, M, Johnson DA, Parker MA, Pearce WH. Size matters: The relationship between MMP-9 expression and aortic aneurysm. Circulation. 1997; 96:2228-32. 
McMillan WD, Pearce WH. Inflammation and cytokine signaling in aneurysms. Ann Vasc. Surg. 1997; 11:540-5.

Meng QH, Jamal W, Hart SL, McEwan JR. Application to vascular adventitia of a nonviral vector for TIMP-1 gene therapy to prevent intimal hyperplasia. Hum Gene Ther. 2006; 17:717-27.

Mikami Y, Kyogoku M. Inflammatory abdominal aortic aneurysms. Nippon Rinsho. 1994; 52:2148-51.

Michel JB, Thaunat O, Houard X, Meilhac O, Caligiuri G, Nicoletti A. Topological determinants and consequences of adventitial responses to arterial wall injury. Arterioscler Thromb Vasc Biol. 2007; 27:1259-68.

Momiyama Y, Ohmori R, Taniguchi H, Nakamura H, Ohsuzu F. Association of Mycoplasma pneumoniae infection with coronary artery disease and its interaction with chlamydial infection. Atherosclerosis. 2004;176:139-44.

Moos MPW, John N, Grabener R, Nobman S, Gunter B, Vollandt R, et al. The lamina adventitia is the major site of immune cell accumulation in standart chow-fed apolipoprotein E-deficient mice. Arterioscler Thromb Vasc Biol. 2005; 25:2386-91. 
Moore KJ, Fitzgerald ML, Freeman MW. Peroxisome proliferator -activated receptors in macrophage biology: friend or foe. Curr Opin Lipidol. 2001; $12: 519-27$

Muhlradt PF. Immunomodulation by mycoplasmas: Artifacts, facts and active molecules. In Razin S.; Herrmann R., ed. Molecular biology and pathogenicity of mycoplasmas. New York, NY, Kluwer Academic/ Plenum Publishers, 2002, p.445-72.

Mussa FF, Chai H, Wang X, YAO Q, Lumsden AB, Chen C. Chlamydia pneumoniae and vascular disease: an up date. J Vasc Surg. 2006; 43:13017.

Netea MG, Selzman CH, Kullberg BJ, Galama JM, Weinberg A, Stalenhoef AF, van der Meer JW, Dinarello CA. Acellular components of Chlamydia pneumoniae stimulate cytokine production in human blood mononuclear cells. Eur J Immunol. 2000; 30:541-9.

Nijsten T, Geluyckens E, Colpaert C, Lambert J. Peroxisome proliferatoractivated receptors in squamous cell carcinoma and its precursors. $\mathbf{J}$ Cutan Pathol. 2005; 32:340-7.

Nishimura K, Ikebuchi M, Kanaoka Y, Ohgi S, Ueta E, Nanba E, Ito H. Relationships between matrix metalloproteinases and tissue inhibitor of 
metalloproteinases in the wall of abdominal aortic aneurysms. Int Angiol. 2003; 22:229-38.

Nobre F, Serrano CV. Tratado de Cardiologia - SOCESP. $1^{\text {a }}$ ed. Manole, 2005.

Orbe J, Fernandez L, Rodriguez JA, Rabago G, Belzunce M, Monasterio A, Roncal C, Paramo JA. Different expression of MMPs/TIMP-1in human atherosclerotic lesions. Relation to plaque features and vascular bed. Atherosclerosis. 2003; 170:269-76.

Padilla J, Leung E, Phipps RP. Human B lymphocytes and B lymphomas express PPAR y and are killed by PPAR y agonists. Clin Immunol. 2002; 103:22-33.

Palombo D, Maione M, Cifiello BI, Udini M, Maggio D, Lupo M. Matrix metalloproteinases. Their role in degenerative chronic disease of abdominal aorta. J Cardiovasc Surg. 1999; 40:257-60.

Pasterkamp G, Schoneveld AH, van Wolferen W, Hillen B, Clarijs RJ, Haudenschild CC, Borst C. The impact of atherosclerotic arterial remodeling on percentage of luminal stenosis widely within the arterial system. A postmortem study. Arterioscler Thromb Vasc Biol. 1997; 17:3057-63. 
Patel MI, Melrose J, Ghosh P, Appleberg M. Increased synthesis of matrix metalloproteinases by aortic muscle cells is implicated in the etiopathogenesis of abdominal aortic aneurysms. J Vasc Surg. 1996; 24:8292.

Petersen E, Boman J, Wagberg F, Anqquist KA. Presence of Chlamydia pneumoniae in abdominal aortic aneurysms is not associated with increased activity of matrix metalloproteinases. Eur J Vas Endovasc Surg. 2002; $24: 365-9$

Pires LJ, Gutierrrez PS. Morphometrical quantification of Chlamydia pneumoniae and Mycoplasma pneumoniae in human atherosclerotic abdominal aortic aneurysms. Rev Bras Cir Cardiovasc. 2007; 22:322-31

Pupka A, Skóra J, Kaluza G, Szyber P. The detection of Chlamydia pneumoniae in aneurysms of abdominal aorta and in normal wall of organ donors. Folia Microbiol. 2004; 49:79-82.

Pyo R, Lee JK, Shipley M, Curci JÁ, Mao D, Ziporin SJ, Ennis TL, Shapiro $\mathrm{SD}$, Senior RM, Thompson RW. Target gene disruption of matrix metalloproteinase-9 (gelatinase B) suppresses development of experimental abdominal aortic aneurysms. J Clin Invest. 2000, 105:1641-9. 
Razin S. DNA probes and PCR in diagnosis of Mycoplasma infection. Mol Cell Probes. 1994; 8:497-511.

Razin S, Yogev D, Naot Y. Molecular biology and pathogenicity of mycoplasmas. Microbiol Mol Biol Rev. 1998; 62:1094-156.

Reszka E, Jegier B, Wasowicz W, Lelonek M, Banach M, Jaszewski R. Detection of infectious agents by polymerase chain reaction in human aortic wall. Cardiovasc Pathol. 2008; Epub ahead of print.

Revelo MP, Federspiel C, Helderman H, Fogo AB. Chronic allograft nephropathy: expression and localization of PAI-1 and PPAR y. Nephrol Dial Transplant. 2005; 20:2812-9.

Rijbroek A, Moll FL, von Dijk HA, Meijer R, Jansen JW. Inflammation of the abdominal aortic aneurysm wall. Eur J Vasc Surg. 1994; 8:41-6.

Rose AG, Dent DM. Inflammatory variant of abdominal atherosclerotic aneurysms. Arch Pathol Lab Med. 1981; 105:409-13.

Rottem S. Interaction of Mycoplasmas with host cells. Physiol Rev. 2003; 83:417-32. 
Saikku P, Leïnonen M, Mattila K, Ekman MR, Nieminen MS, Makela PH, Huttunen JK, Valtonen V. Serological evidence of an association of a novel Chlamydia, TWAR, with chronic coronary heart disease and acute myocardial infarction. Lancet. 1988; 2:983-6.

Sakalihasan N, Limet R, Defawe OD. Abdominal aortic aneurysm. Lancet. $2005 ; 365: 1577-89$.

Sambiase NV, Higuchi ML, Reis MM, Stolf N, Oliveira S, Ramires JAF. Preexistence infection, immunosuppressive therapy and accelerated graft coronary atherosclerosis. Atherosclerosis. 2006; 7: 291.

Sandford RM, Bown MJ, London NJ, Sayers RD. The genetic basis of abdominal aneurysms: A review. Eur J Vasc Surg. 2007;33:381-90.

Sartore S, Chiavegato A, Faggin E, Franch R, Puato M; Ausoni S, Pauletto P. Contribution of adventitial fibroblasts to neointima formation and vascular remodeling: from innocent bystander to active participant. Circ Res. 2001; $89: 1111-21$

Sasaki S, Yasuda K, Takigami K, Yamauchi H, Shiiya N, Sakuma M. Inflammatory abdominal aortic aneurysms and atherosclerotic abdominal aortic aneurysms - Comparison of clinical features and long terms results. Jpn Circ J. 1997; 61:231-5. 
Schiffrin E. Peroxisome proliferators - activated receptors and cardiovascular remodeling. Am J Physiol Heart Circ Phisyol. 2005; 288:H1037-43.

Schmidt R, Redecke V, Breitfeld Y, Wantia N, Miethke N, Massberg S, et al. EMMPRIN (CD 147) is a central activator of extracellular matrix degradation by Chlamydia pneumoniae - infected monocytes, implications for plaque rupture. Thromb Haemost. 2006; 95:151-8.

Schoen, F.J. Robbins and Cotran pathologic basis of disease. In Kumar, V.; Abbas, A.K.; Fausto, N. Ed. Elsevier Saunders. 2005; 511-35

Senior RM, Griffin GL, Flizar CJ, et al Human 92- and 72-kilodalton type IV collagenases are elastases. J Biol Chem. 1991; 266:7870-5.

Shah PK. Inflammation, metalloproteinase, and increased proteolysis - an emerging pathophysiological paragidm in aortic aneurysm. Circulation. 1997; 96:2115-7.

Shi Y, Tokunaga O. Chlamydia pneumoniae and multiple infections in the aorta contribute to atherosclerosis. Pathology International. 2002; 5275563. 
Shimizu K, Libby P, Mitchell N. Local cytokine environments drive aneurysms formation in allograft aortas. Trends Cardiovasc Med. 2005; 15:142-8.

Shimizu K, Mitchell NR, Libby P. Inflammation and cellular immune response in abdominal aortic aneurisms. Circulation. 2006; 26:987-94.

Shimizu T, Kida Y, Kuwano K. A dipalmitoylated lipoprotein from Mycoplasma pneumoniae activates NF-KB through TLR-1, TLR-2, and TLR6. J Immunol. 2005; 175:4641-6.

Silence J, Lupu F, Collen D, Lijnen HR. Persistence of atherosclerotic plaque but reduced aneurysms formation in mice with stromelysin-1 (MMP-3) gene inactivation. Arterioscler Thromb Vasc Biol. 2001; 21:1440-5.

Sluijter JPG, Pulskens WPC, Schoneveld AH, Velema E, Stijder CF, Moll F. et al. Matrix metalloproteinase 2 is associated with stable and matrix metalloproteinases 8 and 9 with vulnerable carotid atherosclerotic lesions: a study in human endarterectomy specimen pointing to a role for different extracellular matrix metalloproteinase inducer glycosylation forms. Stroke. 2006; 37:235-9. 
Soumian S, Gibbs R, Davies A, Albrech TC. mRNA expression of genes involved in lipid efflux and matrix degradation in occlusive and ectatic disease. J Clin Pathol. 2005; 58:1255-60.

Spinelli SL, O'Brien JJ, Bancos S, Lehmann GM, Springer DL, Blumberg N, Francis CW, Taubman MB, Phipps RP. The PPAR-platelet connection: modulators of inflammation and potential cardiovascular effects. PPAR Res. 2008; 2008:328172.

Stintzing S, Heuschmann P, Barbera L, Ocke, M, Jung A, Kirchner T, Neureiter D. Overexpression of MMP-9 and tissue factor in unstable carotid plaques associated with Chlamydia pneumoniae, inflammation, and apoptosis. Ann Vasc Surg. 2005;19:310-9.

Takemoto M, Takigami C, Sakamoto M, Nakano R. Inflammatory abdominal aortic aneurysms and Chlamydia pneumoniae. Int J Cardiol. 2005; 100:50910.

Tambiah J, Powell JT. Chlamydia pneumoniae antigens facilitate experimental aortic dilatation: Prevention with azithromycin. J Vasc Surg. 2002;36:1011-7.

Tan J, Hua Q, Xin X, Wen J, Liu R, Yahng Z. Impact of the metalloproteinase- 9 / tissue inhibitor of metalloproteinase-1 system of large 
arterial stiffness in patients with essential hypertension. Hypertens Res. $2007 ; 30: 959-63$.

Tavares V, Hirata MH, Hirata RDC. Receptor ativado por proliferadores de peroxissoma gama: Estudo molecular na homeostase da glicose, metabolismo de lipídeos e abordagem terapêutica. Arq Bras Endocrino Metab. 2007; 51:526-33.

Tellides G. Periadventitial fat. Regional source of inflammation in atherosclerosis. Arch Pathol Lab Med. 2007; 131:346-7.

Theocharis S, Kanelli H, Politl E, Margeli A, Karkandaris C, Philippides T, Koutselinis A. Expression of peroxisome proliferators-activated receptorgamma in non-small cell lung carcinoma: correlation with histological type and grade. Lung Cancer. 2002; 36:249-55.

Thompson RW, Holmes DR, Mertens RA, Liao S, Botney MD, Mechan RP, et. al. Production on a localization of 92 kilodalton gelatinase in abdominal aortic aneurysms - An elastolitic metalloproteinase expressed by aneurysm infiltrating macrophages. J Clin Invest. 1995; 96:318-26.

Thompson MM, Jones L, Nasim A, Sayers RD, Bell PR. Angiogenesis in abdominal aortic aneurysms. Eur J Vasc Edovasc Surg. 1996; 11:464-9. 
Tontonoz P. PPAR gamma promotes monocyte/macrophage differentiation and uptake of oxidized LDL. Cell. 1998; 93:241-52.

Touyz RM, Schiffrin EL. Peroxisome proliferator-activated receptors in vascular biology - molecular mechanisms and clinical implication. Vasc Pharmacol. 2006; 45:19-28.

Uemura R, Tanabe J, Yokoyama H, Ohakl M. Impact of histological plaque characteristics on intravascular ultrasound parameters at culprit lesions in coronary artery diease. Int Heart J. 2006; 47:683-93.

van der Wal KG. Medial thinning and atherosclerosis - evidence for evidence for involvement of a local inflammatory effect. Atherosclerosis. 1993; 103:55-64.

Vehmaan-Kreula P, Puolakkainen M, Sarvas M, Welgus HG, Kovanen PT. Chlamydia pneumoniae proteins induce secretion of the $92 \mathrm{kDa}$ gelatinase by human monocyte - derived macrophages. Arterioscler Thromb Vasc Biol. $2001 ; 21: 1-8$.

Vela D, Buja M, Madjid M, Burke A, Nagavi M, Willerson JT, Casscells W, Litovsky S. The role of periadventitial fat in atherosclerosis. An adipose subset with potential diagnostic and therapeutic implications. Ach Pathol Lab Med. 2007; 131:481-7. 
Vink A, Pasterkamp G, Poppen M, Schoneveld AH, de Kleijn DP, Roholl PJ Fontijn J, Plomp S, Borst C. The adventitia of atherosclerotic coronary arteries frequently contain Chlamydia pneumoniae. Atherosclerosis. 2001; 57:p.117-22.

Visse $R$, Nagase $H$. Matrix metalloproteinases and tissue inhibitors of metalloproteinases. Structure, function, and biochemistry. Cir Res. 2003; 92:827-39.

Wakino S, Kintscher U, Lu Z, Kim S, Yin F, Ohba M, Kuroki T, Schonthal AH, Hsueh WA, Law RE. Peroxisome proliferator activated receptor gamma ligands inhibit mitogenic induction of p21 (Cip-1) by modulating the protein kinase C delta patway in vascular smooth muscle cell. J Biol Chem. 2001:276:47650-7.

Wanhainen A, Berqvist D, Boman K, Nilson TK, Rutegard J, Bjork M. Risk factors associated with abdominal aortic aneurysm: a population-based study with historical and current data. J Vasc Surg. 2005; 41:390-6.

Wassef M, Upchurch GR, Kuivaniemi H. Challenges and opportunities in abdominal aortic aneurysm research. J Vas Surg. 2007; 45:192-8. 
Wilson WR, Anderton M, Schwalbe EC, Jones JL, Furness PN, Bell PR, Thompson MM. Matrix metalloproteinase- 8 and -9 are increased at the site of abdominal aortic aneurysm rupture. Circulation. 2006; 113:438-45.

Wynn TA. Cellular and molecular mechanisms of fibrosis. J Pathol. 2008; 214:199-210.

Xu C, Zarins CK, Glagov S. Aneurysmal and occlusive atherosclerosis of the human abdominal aorta. J Vasc Surg. 2001; 33:91-6.

Yamashita A, Noma T, Nakazawa A, Saito S, Fujioka K, Zempo N. et al. Enhanced expression of matrix metalloproteinase- 9 in abdominal aortic aneurysms. World J Surg. 2001; .25:259-65.

Yan AT, Yan RT, Spinale FG, Afza R, Gunasinghr HR, Arnold M, Demers C, Mckelvie RS, Liu PP. Plasma matrix metalloproteinase-9 level is correlated with left ventricular volumes and ejection fraction in patients with heart failure. J Card Fail. 2006; 12:514-9.

Yun AJ, Doux JD, Bazar KA, Lee PY. Adventitial dysfunction and evolutionary model for understanding atherosclerosis. Med Hypothesis. $2005 ; 65: 962-5$. 
Zarins CK, Xu C, Glagov S. Atherosclerotic enlargement of the human abdominal aorta. Atherosclerosis. 2001; 155:157-64.

Zhang J, GE H, Wang C, Guo TB, He Q, Shao Q, Fan Y. Inhibitory effect of PPAR on the expression of EMMPRIN in macrophages and foam cells. Int $\mathbf{J}$ Cardiol. 2007; 117:373-80. 